\title{
GEOPHYSICAL SURVEY REPORT
}

\section{PROPOSED WIND FARM AND SUBMARINE CABLE ROUTE}

\section{HULL, MASSACHUSETTS}

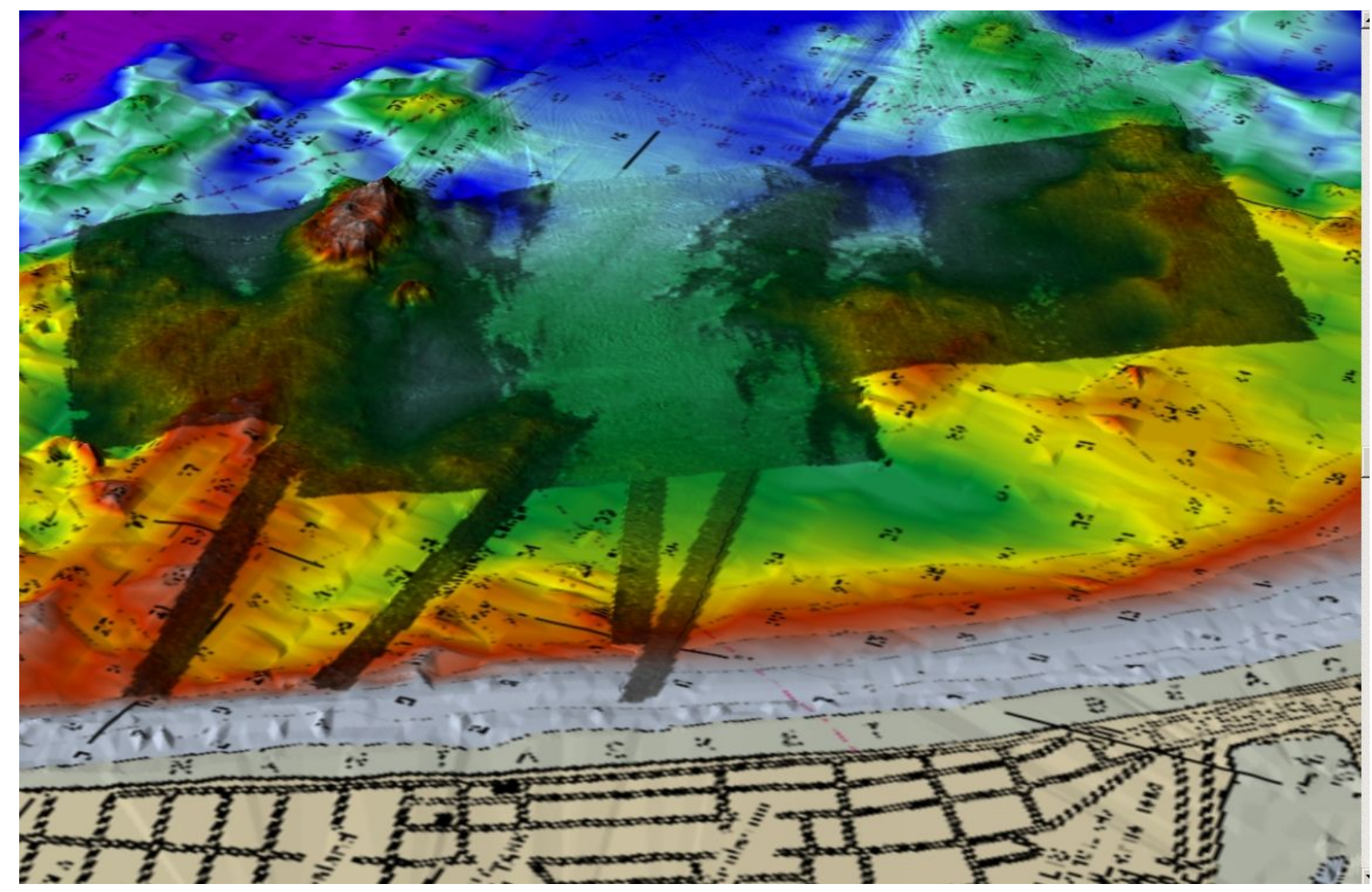

3-D Bathymetric Surface Model with Side Scan Sonar Overlay Hull Windfarm Survey Area

\section{Prepared for:}

GZA GeoEnvironmental, Inc.

140 Broadway

Providence, RI 02903

\section{Prepared by:}

CR Environmental, Inc.

639 Boxberry Hill Rd.

East Falmouth, MA 02536 
Geophysical Survey Report Proposed Wind Farm and Submarine Cable Route, Hull, MA September 2008 CR Environmental, Inc.

\section{TABLE OF CONTENTS}

PAGE

EXECUTIVE SUMMARY

$1.0 \quad$ INTRODUCTION......................................................... 3

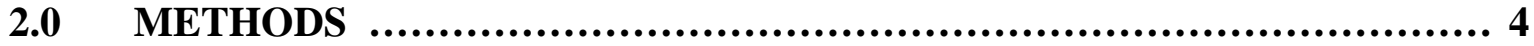

2.1 Navigation and Survey Control 4

$2.2 \quad$ Bathymetric Methods 5

2.2.1 Bathymetric data acquisition $\quad 5$

$\begin{array}{lll}\text { 2.2.2 } & \text { Bathymetric data processing } & 6\end{array}$

$\begin{array}{lll}2.3 & \text { Side Scan Sonar Methods } & 7\end{array}$

$\begin{array}{lll}\text { 2.3.1 Side scan sonar acquisition } & 7\end{array}$

$\begin{array}{lll}\text { 2.3.2 Side scan sonar processing } & 7\end{array}$

2.4 Sub-bottom Sonar Methods 9

$\begin{array}{lll}2.4 .1 & \text { Shallow sub-bottom sonar data acquisition } & 10\end{array}$

$\begin{array}{ll}\text { 2.4.2 Shallow sub-bottom sonar processing } & 10\end{array}$

$\begin{array}{ll}\text { 2.4.3 Deep sub-bottom sonar acquisition } & 10\end{array}$

$\begin{array}{ll}\text { 2.4.4 Deep sub-bottom sonar processing } & 11\end{array}$

$\begin{array}{lll}2.5 & \text { Magnetometry Methods } & 12\end{array}$

$\begin{array}{ll}\text { 2.5.1 } & \text { Magnetic Data Acquisition } \\ \end{array}$

$\begin{array}{ll}\text { 2.5.2 Magnetic Data Processing } & 12\end{array}$

$3.0 \quad$ RESULTS................................................................. 14

$\begin{array}{lll}3.1 & \text { Bathymetric Results } & 14\end{array}$

$\begin{array}{lll}3.2 & \text { Side Scan Sonar Results } & 14\end{array}$ 
Geophysical Survey Report Proposed Wind Farm and Submarine Cable Route, Hull, MA September 2008 CR Environmental, Inc.

$\begin{array}{lll}\text { 3.3 Sub-bottom Sonar Results } & 16\end{array}$

3.3.1 “Shallow” $10 \mathrm{kHz}$ sub-bottom profiling sonar results $\quad 16$

$\begin{array}{ll}\text { 3.3.2 } & \text { Boomer sub-bottom profiling sonar results } \\ \end{array}$

$\begin{array}{lll}3.4 & \text { Magnetic Mapping } & 21\end{array}$

4.0 CONCLUSIONS AND RECOMMENDATIONS............................... 21

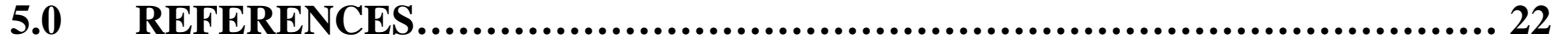

PHOTOGRAPHS

PHOTOGRAPH 1 R/V Sakonnet towing a sub-bottom profiler on the Geophysical Survey

PHOTOGRAPH 2 R/V Lophius collecting bathymetric, side scan sonar, and magnetic data

\section{LIST OF TABLES}

TABLE 1 Magnetic Anomalies

\section{LIST OF FIGURES}

FIGURE 1 Survey Design

FIGURE 2 Bathymetric Contour Map

FIGURE 3 Side Scan Sonar Mosaic

FIGURE 4 Side Scan Sonar Assessments of Likely Substrate Types

FIGURE 5 Side Scan Sonar Mosaic of WTG Alignment

FIGURE 6 Side Scan Sonar Mosaic of WTG-1

FIGURE 7 Side Scan Sonar Mosaic of WTG-2

FIGURE 8 Side Scan Sonar Mosaic of WTG-3 
Geophysical Survey Report Proposed Wind Farm and Submarine Cable Route, Hull, MA September 2008 CR Environmental, Inc.

\section{FIGURES (continued)}

FIGURE 9 Side Scan Sonar Mosaic of WTG-4

FIGURE 10 Side Scan Sonar Mosaic of Cable Route No. 1

FIGURE 11 Detail Side Scan Sonar Mosaic of Cable Route No. 1

FIGURE 12 Side Scan Sonar Mosaic of Cable Route No. 2

FIGURE 13 Detail Side Scan Mosaic of Cable Route No.2

FIGURE 14 Side Scan Sonar Mosaic of Cable Route No. 4

FIGURE 15A Detail 1- Side Scan Sonar Mosaic of Cable Route No. 4

FIGURE 15B Detail 2- Side Scan Sonar Mosaic of Cable Route No. 4

FIGURE 16 Side Scan Sonar Mosaic of Cable Route No. 5

FIGURE 17 Detail Side Scan Sonar Mosaic of Cable Route No. 5

FIGURE 18 Isopach Map Depicting Thickness of Superficial Reflector from "Shallow" Sub-bottom Sonar

FIGURE 19 Annotated 10-KHZ Sub-Bottom Sonar Profile 1

FIGURE 20 Annotated 10-KHZ Sub-Bottom Sonar Profile 2

FIGURE 21 Isopach Map Depicting the Estimated Minimum Depth to Acoustic Basement

FIGURE 22 Sample 0.5-2.0 kHz Boomer Profile

FIGURE 23 Magnetic Contour Map -Total Field

FIGURE 23A Magnetic Contour Map -Total Field Area “C”

FIGURE 24 Magnetic Contour Map-Pole Reduced 
Geophysical Survey Report Proposed Wind Farm and Submarine Cable Route, Hull, MA September 2008 CR Environmental, Inc.

\section{LIST OF APPENDICES}

APPENDIX A Figure of Proposed Boring and Vibracoring Locations

Vibracore Logs with Locations May 2008, ESS Group, Inc.

Sub-Bottom Boomer Profiles at the Proposed Boring Locations Provided to GZA August 2007

Sub-Bottom Boomer Profiles at the Proposed Boring Locations Provided to GZA June 2008

WTG Centerline Sub-bottom Boomer Profile Showing the Estimated Thickness of Acoustically Transparent Overburden

Hull Wind Farm Site Assessment-Boomer Seismic Survey, 8 May 2008, Allen M. Gontz, Coastal Geology \& Geophysics, University of Massachusetts- Boston

Boring Logs and Locations June 2008, GZA GeoEnvironmental, Inc.

2008 Logged Boring Data for B-4 and B-5 Co-located with 2007 Seismic Data

APPENDIX B Limitations for Geophysical Surveys

\section{LIST OF ATTACHMENTS}

\section{ATTACHMENT 1 Report CD and Data DVDs}




\section{EXECUTIVE SUMMARY}

CR Environmental, Inc. (CR) was contracted by GZA GeoEnvironmental, Inc. (GZA) to perform hydrographic and geophysical surveys of an approximately 3.35 square mile area off the eastern shore of Hull, Massachusetts. Survey components included:

- Single-beam bathymetry;

- $\quad 100-\mathrm{kHz}$ and 500-kHz side scan sonar;

- Magnetometry; and

- Low to mid-frequency sub-bottom profiling.

The initial bathymetric and geophysical surveys were conducted between August 20 and 24, 2007. During the survey operation, preliminary bathymetric, side scan, estimated depth to bedrock, and magnetic maps were delivered to GZA. This near real-time data was provided to on-shore team members selecting locations for the four Wind Turbine Generators (WTGs) within survey areas “A” and "B”, and the cable routes to survey between the turbines. Three potential cable routes (Cable Routes Nos. 1, 2, and 4) to shore were also surveyed (Figure 1).

On May 8, 2008 Area “C”, a shoreward extension of Area “A”, and a fourth cable route to shore (Cable Route No. 5) were surveyed to obtain geophysical data at planned boring locations that fell outside of the 2007 survey area. Data on sediment characteristics provided by the twelve vibracore samples collected by CR and ESS Group, Inc. (ESS) in May 2008, and the two deep exploratory borings collected by GZA and Warren George in June 2008 supported the geophysical survey results. A summary of the survey results and data interpretation presented in this report is provided below:

- The bathymetric survey documented bottom elevations relative to Mean Lower Low Water (MLLW). The minimum reported elevation within the survey area was -62.18 feet MLLW near the easterly extent of the survey area. The average elevation was -39.3 feet MLLW. It is noteworthy that the geophysical data suggest much of the survey area is a 
high-energy dynamic environment, and bottom elevations likely change following storm events.

- The side scan sonar survey suggests that the site is dominated by gravel, cobble and boulder substrates, bisected perpendicular to shore by low-relief sand substrate. Manmade artifacts observed in the data were limited to lobster gear, a cable or chain, and small unidentifiable debris.

- The magnetic survey identified broad-area anomalies associated with site geological processes or formations. Potentially man-made anomalies were scarce and of relatively low magnitude.

- Data from the mid-frequency $(10-\mathrm{kHz})$ continuous wave sub-bottom profiling system for "shallow" sub-bottom penetration suggests the presence of an approximately 3 to $12 \mathrm{ft}$ layer of mobile surficial sand in the central portion of the entire survey area. Penetration (i.e., likely sand thickness) was negligible in coarse substrates (till - gravel, cobble, boulders), and in portions of the northern Cable Routes No. 1 and No. 2 shoreward of survey Area "A". Penetration along the most southerly Cable Routes No. 4 and No. 5 ranged from approximately 2 to $12 \mathrm{ft}$. Penetration in the easterly halves of the southern Cable Routes No. 4 and No. 5 was 8 to $12 \mathrm{ft}$, and decreased shoreward to approximately 2 to $6 \mathrm{ft}$.

- Data from the low frequency (0.5 - $2 \mathrm{kHz}$ ) Boomer “deep” sub-bottom profiling system suggests that the minimum sediment thickness (acoustic basement) in the central sandy portion of the survey area is approximately 70 to 90 feet below the sediment surface. This area may constitute a paleo-channel and associated fluvial deposits. The estimated minimum acoustic basement at the proposed wind turbine generator (WTG) locations was approximately $70 \mathrm{ft}$ at WTG-1 and WTG-2 to nearly 100 feet below the sediment surface at WTG-4. Inferred fractured bedrock was at approximately $90 \mathrm{ft}$ at GZA's Boring 4 in the vicinity of WTG-4. In contrast, the minimum acoustic basement in the 
vicinity of WTG-3 was estimated to be only about 20 feet; likely due to the underlying compacted glacial till observed at Boring 5 which extended to about $90 \mathrm{ft}$.

- Survey data were incorporated into geographical information system (GIS) software, and have been provided digitally in multiple formats suitable for import to both GIS and CAD software.

\subsection{INTRODUCTION}

CR Environmental, Inc. (CR) performed hydrographic and geophysical surveys off Nantasket Beach in Hull, Massachusetts, between August 20 and 24, 2007, and on May 8, 2008. The survey design as specified by GZA GeoEnvironmental, Inc. (GZA) in their Request for Proposal (RFP) was to support the assessment of appropriate installation locations for four proposed wind turbine generators (WTGs) and their associated transmission cables for the Hull Municipal Light Plant. Survey components included single-beam bathymetry, magnetometry, side scan sonar, and sub-bottom sonar using a low frequency Boomer system and a higher frequency $10 \mathrm{kHz}$ continuous wave system. The geophysical surveys were designed to facilitate real-time interpretation of results and the communication of results to team members at GZA, ESS Group, Inc. (ESS), The Public Archaeological Laboratory, Inc. (PAL), and the Renewable Energy Research Laboratory, Department of Mechanical \& Industrial Engineering at the University of Massachusetts.

The survey design included distinct requirements for portions of the survey area regarding the survey line spacing and the instrument suite based on the intended use of the data and the anticipated exploration or construction activities. The final version of the RFP specified a transect spacing of 200 feet (ft) for the near-shore area of interest Area "A" (approximately 1.6 square miles) and a 1,500 ft transect spacing for the offshore area of interest Area "B" (approximately 1.2 square miles). A closer transect spacing of $50 \mathrm{ft}$ was specified for selected WTG locations, connecting cable routes between WTGs, and for the 3 cable routes between the WTGs and points on shore. Figure 1 shows survey transects and instrumentation deployed for each portion of the survey. The full instrument suite that included the Boomer sub-bottom 
profiler is depicted as the black lines on Figure 1, and was required at Areas " $\mathrm{A}$ " and " $\mathrm{B}$ " and the outer lines of the cable routes and WTG connecting routes. A shoreward extension of Area "A" (approximately 0.21 square miles) and a fourth cable route were added in May 2008 to obtain geophysical data at planned boring locations that were outside the initial survey area. Transect spacing and instrumentation for the new Area "C" and Cable Route 5 matched those specified for Area "A" and previously surveyed cable routes.

Survey transects were digitally created using HYPACK hydrographic survey software. Background imagery including nautical charts, NOAA bathymetric data and USGS/NOAA backscatter data (Ackerman et al., 2006) were imported to HYPACK to aid survey design and on-the-fly analysis.

Mobilization of geophysical instrumentation for the survey events was conducted on Monday August 20, 2007 and on May 7, 2008 . Two survey vessels took part in both field efforts. Each vessel was equipped with HYPACK navigation and data acquisition software, and a Trimble Differential Global Positioning System (DGPS) capable of digitally outputting sub-meter horizontal positions at $1 \mathrm{~Hz}$. The $35 \mathrm{ft} \mathrm{R} / \mathrm{V}$ Sakonnet was outfitted with the sub-bottom profiling equipment, including a 10-kHz SyQwest StrataBox profiler and an Applied Acoustics Boomer profiling system (Photograph 1). The $26 \mathrm{ft}$ R/V Lophius was equipped with a Marine Magnetics, Inc. Explorer magnetometer, a SyQwest HydroBox precision digital echosounder, and an Edgetech side scan sonar system (Photograph 2).

\subsection{METHODS}

\subsection{Navigation and Survey Control}

Navigation for the surveys was accomplished using a Trimble AgGPS 132 12-channel Differential Global Positioning System (DGPS) system capable of receiving the U.S. Coast Guard (USCG) Beacon corrections as well as OmniStar subscription-based satellite differential corrections. The system is capable of sub-meter (i.e., less than one-meter) horizontal position accuracy. The DGPS system was interfaced to a laptop computer running HYPACK MAX 
hydrographic survey software. HYPACK continually recorded vessel position, DGPS satellite quality and provided a steering display for the vessel captain.

NOAA’s published offsets between the Inner Harbor Tide Station (\#8443970) and Boston Light, approximately 2 miles from the survey area, shows a magnitude correction of only 5\% for high tide and 3\% for low tide, and a negligible time delay of 1 to 2 minutes. Therefore, the data from NOAA's Inner Harbor Station were used for bathymetric data normalization. A MiniTroll data logging tide gage was installed at Boston Light on the morning of August 21, 2007. The purpose of the installation was to provide a backup source of water level data in the event that the NOAA Boston Tide Station ceased operation during the survey effort.

\subsection{Bathymetric Methods}

\subsubsection{Bathymetric data acquisition}

The bathymetric data acquisition system consisted of a laptop computer running HYPACK hydrographic survey software, a precision single-beam echo sounder and a Trimble DGPS. The echosounder and DGPS were interfaced to the survey computer via RS-232 serial ports.

Depth measurements were collected in August 2007 using a SyQwest, Inc. HydroBox precision echosounder equipped with an 8-degree $200-\mathrm{kHz}$ transducer. The echosounder accurately digitized and recorded the seabed in proprietary *.odc format (a variant of SEGY) and exported depth values to HYPACK data acquisition software. Dynamic adjustments to signal gain and range were made as necessary to ensure high quality data. Depth measurements were collected in May 2008 using an ODEC Bathy500-MF echosounder equipped with a 3-degree $200 \mathrm{kHz}$ transducer. During both survey efforts, the echosounder's transducer was mounted to the rail of the survey vessel amidships using a high strength adjustable boom. The DGPS antenna was attached to the top of the transducer boom, eliminating the need to correct for horizontal offsets. The transducer depth below the water surface was checked and recorded at the start and end of each day. 
The accuracy of both echosounders is approximately $0.1 \%$ of the water depth with a resolution of $0.1 \mathrm{ft}$. System accuracy was checked at the start and end of each survey day by comparing echosounder water depth measurements to known water depths. Known water depths were obtained using the "bar check" method, in which a metal plate was lowered beneath the echosounder's transducer to several known distances (e.g., 5.0, 10.0, 15.0 and $20.0 \mathrm{ft}$ ) below the water surface. "Bar-check" calibrations were consistently accurate to within $0.1 \mathrm{ft}$ throughout the survey.

Additional calibrations were conducted in situ twice per day by collecting water column profiles of sound velocity. Sound velocity in water can be determined based on measurements of temperature and salinity. Measurements of water column temperature and salinity were performed using a Seabird SEACAT-19 CTD water quality profiler. A sound velocity profile was calculated using the Chen equation (Chen and Millero, 1977). Profile data were entered into HYPACK and used to adjust raw soundings.

Redundant backups of bathymetric data were recorded to a removable hard drive at the end of each survey day.

\subsubsection{Bathymetric data processing}

Bathymetric data were processed using the HYPACK Single-Beam Processor Module. Individual transect data were visually inspected in profile format, and components of processing included removal of outlying soundings associated with water column interference (e.g., fish, vegetation, or mid-water column debris), conversion of soundings to MLLW elevations based on water level data recorded at NOAA Inner Harbor Station \#8443970 in Boston, and correction of soundings for variations in sound velocity.

After performing data adjustments, the processed bathymetric data were combined into a single comma-delimited ASCII text file including fields for Northing, Easting, and Elevation. The file of combined data were then imported to Golden Software, Inc. Surfer V.8.1 Surface Modeling Software and a grid of the seabed elevations created using Kriging interpolation methods and a 
$50 \mathrm{ft}$ node interval. A contour map depicting bottom elevations using a $2 \mathrm{ft}$ contour interval was created from this grid and the map was exported in SHP and DXF formats. A second layer was created using conventional hydrographic spectrum shading and this map was exported as a georeferenced TIF image file.

\subsection{Side Scan Sonar Methods}

\subsubsection{Side scan sonar data acquisition}

Side scan sonar data were acquired using an Edgetech, Inc. Model 560 system aboard the R/V Lophius. The system is comprised of an Edgetech 272 TD towfish interfaced to a topside processor via an Analog Control Interface (ACI) circuit. The ACI allowed adjustment of both port and starboard signal gains as judged necessary by the sonar operator. Control of the ACI and sonar signal settings was accomplished using Chesapeake Technology, Inc. SonarWizMAP acquisition software.

Sonar data for the wide area survey of Areas "A", "B" and "C" were collected using a 100-kHz signal and $184 \mathrm{ft}$ (56 meter) range scale. A $500 \mathrm{kHz}$ signal producing higher resolution data and an $82 \mathrm{ft}$ (25 meter) range setting were used to collect sonar data at the selected WTG locations and cable routes. The length of towfish cable deployed relative to the DGPS antenna (i.e., layback) was recorded for each line to aid in towfish positioning during processing.

All data were archived to a removable hard drive at the end of each survey day. Draft sonar mosaics were produced regularly in the field to ensure adequate survey coverage and to allow identification of noteworthy features.

\subsubsection{Side scan sonar processing}

Sonar data were processed using a combination of Chesapeake Technology, Inc. SonarWeb software and HYPACK's implementation of GeoCoder software developed by scientists at the University of New Hampshire / NOAA Center for Coastal and Ocean Mapping Joint 
Hydrographic Center (CCOM/JHC). SonarWeb was used to create preliminary sonar mosaics, HTML navigable data files and GIS formatted navigation shapefiles. GeoCoder was used to create superior final mosaics using innovative beam-angle correction algorithms. Processing of raw side scan sonar data in SonarWeb and GeoCoder consisted of:

- Corrections for towfish layback (i.e., the distance between the towfish and the DGPS antenna),

- Data adjustments for signal attenuation, and

- Georeferencing of sonar imagery (i.e., projection of the sonar data into real-space coordinates).

Water column portions of the acoustic returns were removed through the inspection and processing of each survey transect. The raw data were then corrected by calculating and applying accurate layback and catenary coefficients (i.e. a factor corresponding to the approximate degree of cable curvature) to each of the data files. Layback and catenary corrections were calculated from the recorded "cable out" using a simple trigonometric function and the height of the towfish above the seabed. Data were then adjusted for signal attenuation with distance using moderate Time Varied Gain Corrections (TVG). Finally, georeferenced transect data and mosaics were created from these processed data.

Sonar resolution is defined as the ability of the sonar system to discriminate between two adjacent objects of a particular size and separation. This resolution decreases with increasing range from the sensor due to signal spreading. The theoretical resolution of the side scan sonar data is determined by swath width (range setting), frequency, beam width, ping duration, and vessel speed. Data collected for the wide area surveys using a 100-kHz signal and 56 meter range has a resolution of approximately 10 to $50 \mathrm{~cm}$ ( 4 to 20 inches) depending on the range (i.e. the distance from the towfish). Data collected at WTGs and Cable Routes using a $500 \mathrm{kHz}$ signal and 25 meter range has a resolution of approximately 5 to $25 \mathrm{~cm}(\sim 2$ to 10 inches) depending on the range. 
The resolution of georeferenced imagery was set to $0.5 \mathrm{ft}$ per pixel (about $15 \mathrm{~cm}$ ). This slightly exceeds the mid-range resolution of the $100 \mathrm{kHz}$ sonar while taking advantage of the higher 500 $\mathrm{kHz}$ resolution. Note that sonar "waterfall” imagery (uncorrected raw data) resolution was not constrained by this pixel size determination.

Side-scan sonar data processed in SonarWeb were delivered in several forms including: georeferenced JPG files, high-resolution annotated "waterfall” imagery of each survey lane, and GIS shapefiles (polygons) of transect navigation data with the width of the polygons corresponding to sonar range settings. Also, a set of HTML files for the project was created, allowing Web-browser (i.e., Internet Explorer or Netscape) access to all survey data and imagery. Georeferenced sonar data were incorporated in a GIS database for comparison with other data. Because of the degree of overlap between navigation polygons, the navigation shapefiles are best queried and analyzed in ESRI ArcMAP 9.0 (or later). It is also important to note that while the mosaics produced for this report included all projected sonar files, users of ArcMAP can create customized mosaics of areas of specific interest by selectively adding data for individual transects and adjusting image transparency and contrast. In some instances, selective removal of the extensively overlapped sonar data may result in a "clearer" image. Files produced using SonarWeb are projected (when applicable) to the Massachusetts Mainland State Plane Grid, NAD83, US Survey Foot. Mosaics created using GeoCoder have been projected to UTM Zone 19N, NAD83, US Survey foot.

\subsection{Sub-bottom Sonar Methods}

Sub-bottom sonar data were collected aboard the R/V Sakonnet. The separation of sub-bottom profiling instrumentation from higher frequency hydrographic systems (e.g., side scan and bathymetry) minimized intersystem interference and the anticipated severe degradation of the geophysical data quality. 


\subsection{1 "Shallow" sub-bottom sonar data acquisition}

To focus on near-surface sediment, stratigraphic data were collected simultaneously during the bathymetric and side scan sonar surveys using a SyQwest 10-kHz Stratabox sub-bottom profiling system on the same set of survey transects. This Stratabox system consists of a cone-shaped transducer mounted to a vertical boom on the amidships rail, an on-board signal processor and amplifier, and a data acquisition computer. Data were recorded in .odc format using proprietary StrataBox software run on a dedicated laptop computer. The computer was interfaced to the DGPS through a serial port. Offsets between the transducer and the DGPS antenna were recorded to allow for position correction during data processing. Data were archived to a portable hard drive at the end of each survey day.

\subsection{2 "Shallow" sub-bottom sonar processing}

Stratabox $10-\mathrm{kHz}$ profile data were processed using Chesapeake Technology's SonarWeb software. Appropriate adjustments to TVG were made during processing. Sub-bottom profiles were exported in JPG format with accompanying HTML-navigable indices and GIS shapefiles (polygons) of transect navigation data, with the width of the polygons corresponding to sonar range settings. The sediment surface and first shallow reflector, likely representing mobile sands were digitized and exported in an ASCII database consisting of Northing, Easting and thickness values. This database was used to create a map of shallow strata. Several sample profiles were selected and annotated to illustrate data quality, penetration and near-surface geology.

\subsection{3 “Deep" sub-bottom sonar acquisition}

An Applied Acoustics Engineering CAT200 Boomer seismic system was employed to provide sediment thickness to bedrock. The CAT200 is a surface-towed, catamaran-mounted system that uses a bi-metal plate embedded in an epoxy resin to create a broadband, spherical acoustical pulse. The CAT200 is coupled with a surface-towed Applied Acoustic Engineering 20-element 
hydrophone tuned for use with the CAT200. Electrical energy used to create the acoustical pulse is generated via an Applied Acoustics CSP150 signal generator. The CSP150 is triggered from a topside acquisition and recording system running Chesapeake Technologies, Inc. SonarWiz acquisition software and integrated with the DGPS. SonarWiz is also used to view real time field data and log data to a local hard drive.

The CAT200 system has a peak frequency response between 500 and $2000 \mathrm{~Hz}$. This results in approximately a $20 \mathrm{~cm}$ ( 8 inch) vertical resolution with horizontal resolution controlled by vessel speed. The peak frequency also allows for excellent penetration and response from unconsolidated sediments.

Due to its frequency and power the CAT200 Boomer seismic system penetrates to bedrock and over consolidated sediments. The deepest penetration is referred to as the acoustic basement. In the Boston area the acoustic basement is represented by materials such as glacial till, bedrock and thick gravel beds.

\subsection{4 “Deep" sub-bottom sonar processing}

Field data were post-processed to provide high-resolution imagery for interpretation using IXSEA, Inc. Delph Map Suite and Seismic GIS. Individual field lines were opened and processed by applying band-pass filters, time-varying gain and background removal.

After post processing, the imagery was interpreted for: 1) seafloor; 2) acoustic basement; and 3) paleo-channel sediments. Individual reflectors were digitized for each line and exported in HTML format. Data for each transect were then merged in MS-DOS and converted to a single master comma-separated-variable (csv) formatted X, Y, Z (thickness) database for gridding and plotting.

Boomer profile data were also processed using SonarWeb and converted to JPG image format with associated HTML-navigable indices and GIS navigation data. These profiles are included on the Project data DVD (Attachment 1). 


\subsection{Magnetometry Methods}

\subsubsection{Magnetic data acquisition}

Magnetic data were collected simultaneously with the bathymetric and side scan sonar data along the same set of survey transects aboard the R/V Lophius. Magnetic data were acquired using a Marine Magnetics, Inc. MiniExplorer high resolution marine magnetometer system. The magnetic data acquisition system consisted of a towfish-mounted Overhauser magnetic sensor and pressure/depth sensor, an onboard power supply and serial interface, and a data acquisition computer. The $1 \mathrm{~Hz}$ data stream from the magnetic sensor was routed to the HYPACK navigation computer via a serial port, and HYPACK recorded magnetic readings in gammas (1.0 gamma = 1 nanoTesla) as a separate field within the same raw data file containing bathymetric soundings. The position of the magnetometer towfish was calculated in real-time using a HYPACK mobile device driver which considered "cable out" relative to the DGPS antenna, the cable catenary curve, and the effects of vessel course corrections.

The magnetometer towfish was kept as close to the seabed as practical. Towfish depth was modified by adding lead weight to the tow cable in 10-pound increments. The sensor was consistently deployed at a great enough distance from the survey vessel to preclude the potential for magnetic interference from the hull or the vessel's electronics.

\subsubsection{Magnetic data processing}

Magnetometer data were processed using HYPACK's Single-Beam Processor Module. Each magnetic survey transect was first inspected in profile format for characteristic signals which indicate the presence of ferrous anomalies. Observed anomalous signals were digitized to an ASCII database including fields for position, approximate magnitude (in gammas), and shape. Signal shape classifications included Dipolar (DP), Monopolar (MP) and Monopolar negative (MP-). It is possible that some of these anomalous point measurements were associated with rough sea states rather than ferrous objects. 
After inspecting each data file and digitizing anomalies, magnetic measurements were merged into a single ASCII comma-delimited database containing all total field (TF) magnetic intensity measurements for the entire survey area. Due to temporal variations in the Earth's magnetic field, separate databases and maps of TF magnetism have been created for data collected in August 2007 and May 2008. The databases contain fields for Northing, Easting, and magnitude. Each data set was imported to Golden Software, Inc. Surfer V.8.1 Surface Modeling Software. Grids of magnetic intensity were created using triangulation interpolation methods and a $50 \mathrm{ft}$ node interval. Contour maps were created from these grids depicting TF magnetism using a 1gamma contour interval and the maps were exported in SHP and DXF formats. A second set of maps were created using spectrum shading and these maps were exported as georeferenced TIF image files.

The final magnetic data processing procedure employed is the "Pole-Reduction" technique. This method minimizes background magnetic interference associated with geologic structures and temporal/diurnal magnetic variations by transforming total field measurements into gradient values. Data were transformed by subtracting sequential TF values and replacing the original values with the difference (e.g., Pole Reduced value or "Gratio": where PR value $=54,390.91$ gammas $-54,391.97$ gammas $=-1.06$ gammas).

All TF magnetic data were transformed into this pole-reduced (PR) form and merged into a single ASCII comma-delimited database including fields for Northing, Easting, and "Gratio" (in gammas). This combined data set was imported to Golden Software, Inc. Surfer V.8.1 Surface Modeling Software. A grid of "relative” magnetic intensity was created using triangulation interpolation methods and a $50 \mathrm{ft}$ node interval. A contour map of pole-reduced magnetism using a 1-gamma contour interval was created from this grid, and the map exported in SHP and DXF formats. A second map was created using spectrum shading, and exported as a georeferenced TIF image file. 


\subsection{RESULTS}

\subsection{Bathymetric Results}

Site bathymetry using a 2.0-ft contour interval is shown on Figure 2. Elevations are reported relative to Mean Lower Low Water (MLLW) using the current tidal epoch. The minimum reported elevation within the survey area was 62.18 feet below MLLW near the easterly extent of the survey area. The average elevation was 39.3 feet below MLLW.

Approximately co-located soundings collected on perpendicular transects were statistically compared to evaluate sounding accuracy following U. S. Army Corps of Engineers specifications (US ACOE, 2002. EM1110-2-1003. Ch. 3). These comparisons resulted in an arithmetic mean difference between 108 co-located soundings of $-0.1 \mathrm{ft}$ (bias) and an absolute difference of $0.4 \mathrm{ft}$. The $95^{\text {th }}$ percentile elevation accuracy was calculated as 0.76 feet. All of these values are well below the minimum tolerances for hydrographic surveys specified by the US ACOE. The largest sources of errors were likely the rough seafloor (boulder/cobble) and rough sea state on two of the survey days.

\subsection{Side Scan Sonar Results}

Side scan sonar results are presented as mosaics of gray shaded information. The shade of gray corresponds to the strength of the returning signal and is used to infer bottom type (sediment texture and roughness) and to identify underwater structures or debris. A key to sonar shading is provided below.

Key to Side-scan Sonar Image Shading CONVENTIONAL SCALE 
In general, weak signal returns correspond to smooth seabed substrates (e.g., fine sediments with little microtopography), soft materials that absorb the signal, or seabed sloping away from the signal source (towfish). These features appear lighter gray in sonar imagery.

Strong signal returns correspond to rough seabed substrates (e.g., gravel, cobble), highly reflective materials, or to a seabed sloping towards the signal source. These features appear as dark gray to black in the sonar imagery.

Features that rise above the seabed (e.g., boulders) reflect more of the sonar energy than the surrounding substrate resulting in strong signal returns due to the decreased angle of incidence. These features often prevent insonification of the area opposite the signal source, resulting in a sonar "shadow" (white imagery). The length of these shadows can be used to calculate the approximate height of the feature above the seabed.

A mosaic of the side scan sonar data for the wide-area surveys is shown on Figure 3. Bottom types are indicated on an annotated version of the mosaic (Figure 4). Harding Ledge and Strawberry Ledge are clearly depicted on the sonar records. The sonar data suggest that the survey area is dominated by gravel/ cobble/ boulder substrates with a central northeasterly trending area of finer sands (Figure 5). The data show numerous areas of rippled sand or gravel (e.g., Figures 6 and 7). Although the location and extent of these rippled areas roughly corresponds to similar features depicted in the NOAA / USGS backscatter data, comparison of our data with the 2001 backscatter data suggests substantial movement of rippled substrates.

Detailed mosaics for the proposed WTG locations and the WTG alignment are provided as Figures 5 through 9 . These data suggest that WTG-1 may be located in cobble/gravel substrate, WTG-2 may be located in a gravel / sand substrate. The gravel/sand substrate appears continuous between WTG-1 and WTG-2. WTG-3 and WTG-4 appear to be located in low-relief sands.

Detailed mosaics for each of the cable routes are provided as Figures 10 through 17. The data suggest that Cable Route No. 1 is located in gravel and cobble substrate, with the occurrence of boulders increasing with distance from shore (Figures 10 and 11). 
Cable Route No. 2 appears to traverse an area of low relief sand, and intersects small areas of coarser substrate near shore and in the central portion of the survey area (Figures 12 and 13). The increased detail provided by the $500 \mathrm{kHz}$ signal relative to the $100 \mathrm{kHz}$ signal is illustrated on the lower portion of Figure 13.

Cable Route No. 4 intersects each of the substrate classes documented at the site (Figure 14). The shoreward 2,200 feet of this route is located in substrate that appears to be dominated by cobbles, with irregular patches of sand and few boulders. The next 2,000 feet of the route is located in substrate that appears to be dominated by gravel and cobble (see Figure 15A). A linear sonar target consistent with chain or heavy cable bisects the route in this area. This target is associated with low-magnitude magnetic anomalies (see Section 3.4). The central portion of this cable route i.e. the first 2,200 ft surveyed in Area " $A$ " is predominantly low relief sand. The remaining offshore portion of this route transitions to cobble/boulder substrate, with several distinct transitions to low-relief sand and gravel (Figure 14).

Sonar data suggest that the substrate along Cable Route No. 5 is dominated by sands, with a likely increase in grain size as the route approaches shore (Figure 16). Sonar Contacts were not observed along this Route, but dense bottom scars (trough-like scours) were observed in near shore portions of the data (Figure 17). These features are apparently associated with fishing gear used during bottom dredging for surf clams. A local surf clam vessel was observed actively dredging in the area shown on Figure 17 during the May 2008 survey. With the exception of the linear sonar target identified on Cable Route 4 (Figure 15A), and several short trawls of lobster traps, man-made debris was not observed in the sonar data.

\subsection{Sub-Bottom Sonar Results}

\subsection{1 "Shallow" $10 \mathrm{kHz}$ sub-bottom profiling sonar results}

The Stratabox profiling system successfully penetrated up to 40 feet of sandy sediments. Penetration was greatest in the central sandy region of the site (see Figure 18), and negligible 
along the two northern Cable Routes. Penetration along the most southerly Cable Routes No. 4 and No. 5 ranged from approximately 2 to $12 \mathrm{ft}$. Penetration along the eastern half of Cable Routes No. 4 and No. 5 was 8 to $12 \mathrm{ft}$, and declined shoreward to about 2 to $6 \mathrm{ft}$.

A widespread presence of till (i.e. unconsolidated, poorly sorted sediments of glacial origin) was suggested by the side scan sonar data. Where till intersected the ocean bottom large boulders were often seen at the surface and the sub-bottom record showed poor penetration (Figures 19 and 20).

The depth of shallow seismic reflectors was mapped using the Stratabox profiling system. As shown on Figure 19, the Stratabox proved useful in discriminating sandy lenses of both presumed Holocene (post-glacial) and glacial marine origin from presumed till. Thin ( $<1 \mathrm{~m}$ thick) sandy veneers of relatively small extent were sporadically encountered at or near the surface in many portions of the study area. Where the presence of sand was mapped ( $>1 \mathrm{~m}$ thick), it existed as either a rather large sandy region perpendicular to the shore or as small regions, likely depressions (glacial kettles) filled with Holocene sand.

The central sandy region appeared to consist of a series of shallow sloping sandy packages of both Holocene and glacial marine sediments with an overall northeastern trend. Holocene sediments exist at the surface (see Figure 3, the side scan sonar mosaic), and extend 6 to 14 feet below the seabed (see Figures 18 and 20). These sediments are the active and mobile source for bedforms (ripples and dunes). Below these Holocene sediments, presumed glacial marine sediments are present as the direct result of glacial discharge in a sub-aqueous environment during the last glacial maximum (15,000 years ago). The 12 vibracores obtained by CR in this region during the week of May 26, 2008 had penetration depths of four to six feet prior to refusal, and contained predominantly fine sand with traces of medium to coarse sand. The exception was station 10 (Core ID: VC-10A) where silt and fine gravel were also found. These data generally agree with the data results for the shallow penetration sub-bottom profiler. A figure of vibracore locations and the ESS Group, Inc. (ESS) logs are provided in Appendix B. The analytical results from the vibracore will be submitted separately by ESS. 


\subsection{2 “Deep” Boomer sub-bottom profiling sonar results}

Detailed geological interpretations of Boomer sub-bottom profiles are presented in Appendix A.

All Boomer profiles have been provided digitally in JPG format with HTML-navigable indices on the project data DVD in Attachment 1.

Boomer data have been interpreted for depth to the acoustic basement. Acoustic basement, as used in this report, represents the deepest reflector that can be confidently interpreted as unconsolidated sediments. In some instances, that is confidently correlated to bedrock or till based on the characteristics of the reflectors bounding the sequence and the character of the reflectors that occur within the bounding reflectors. In other instances, acoustic basement is a reflector that occurs within the sedimentary sequence and due to factors detailed below the base of the sequence cannot be confidently identified. In the first case, acoustic basement represents sediment thickness. In the second case it represents a minimum sediment thickness.

Figure 21 is a contour map of the estimated minimum depth to acoustic basement based on 2007 and 2008 survey data. An annotated example of a $0.5-2 \mathrm{kHz}$ Boomer profile is shown on Figure 22. On some lines a feature that possessed geophysical characteristics similar to those associated with channel cut and fill structures was observed in each of the surveyed areas (Areas "A", "B" and "C"). Where this feature could be resolved, it was interpreted as a paleo-channel (see Figures 21 and 22). Depth to acoustic basement varied greatly throughout the survey areas. It ranged from coincident with the seafloor in places surrounding Harding Ledge and several areas in the northwestern, southeastern and south central section of the survey area to about $40 \mathrm{~m}$ (130 feet) in the central south sections of Area "A". The most consistent depth to acoustic basement occurs in an east-west band in the central portion of Area " $\mathrm{A}$ " just south of Harding Ledge (Figure 21). It is persistent from the western to the eastern survey limits. This area is also the location of the feature that possesses geophysical characteristics similar to channel cut and fill structures, i.e. the paleo-channel. 
Additional profiles and further interpretation of sub-bottom data along individual lines and at proposed WTG locations and potential boring locations are provided in Appendix A. Also included is a WTG centerline Boomer profile where the thickness of the sand and gravel strata in the vicinity of the proposed wind turbine generator locations is estimated. Profiles were provided to GZA in June 2008 to assist in planning the exploratory boring program. During the week of June 23, 2008, two deep borings, B-4 and B-5 were obtained by GZA and Warren George, Inc. (WGI). Two additional figures showing the logged boring data overlain on the approximately co-located seismic data were produced by CR. The GZA boring logs and CR figures are provided in Appendix A.

Note that the acoustic basement is not the interface between unconsolidated sediments and lithified units, but the limit of penetration and return of acoustical energy. There are numerous factors that can affect the detection of this surface and accuracy of depth measurements, including:

1. Sea state. The surface-towed nature of the acoustic source and hydrophone are susceptible to noise in the water column created by bubbles resulting from increased waves/chop.

2. Water depth. In shallow water, a series of multiple returns are common. These are a result of the acoustic energy penetrating the seafloor, reflecting off a horizon, and instead of being completely absorbed by the air-water interface, energy is reflected back into the water column, penetrates the seafloor and reflects back to the hydrophone. This creates a ghost image of the horizon at multiples of the depth of the original horizon. In shallow water, these multiple ghost images often overprint and obscure the areas of interest and prevent adequate interpretation of the sedimentary sequence.

3. Line orientation. Crossing of geologic features plays a critical role in the ability to interpret the feature. For example, if a feature slopes down to the west and the line is orientated west, the surface will be less likely to be resolved due to scattering of acoustic energy forward and away from the hydrophone. Crossing the same feature to the east will provide optimal resolution as the acoustic energy will be focused toward the hydrophone. 
4. Geological materials. Reflection of acoustic energy is dependent on the difference in acoustic impedance between two layers. If the difference is small, the layer may not be resolved.

5. Layer thickness. The CAT200 system has a vertical resolution of approximately $20 \mathrm{~cm}$ ( $\sim$ inches). Layers that are thinner than $20 \mathrm{~cm}$ may not be resolved or may be hidden in reflection of a given horizon, depending on the difference in acoustic impedance.

6. Attenuation of signal. Acoustical energy is absorbed and scattered by various earth materials. Larger grain-sized sedimentary units tend to scatter more energy and lessen the subsequent returns from deeper in the sequence. This is common when attempting to penetrate thick sequences of stony till.

7. Sound velocity variations in the geological profile. In the absence of empirically determined sound velocity measurements, the common geophysical practice is to assign a value of 1,500 meters per second to the entire profile. Actual velocity values may range from approximately $1,400 \mathrm{~m} / \mathrm{s}$ to $1,800 \mathrm{~m} / \mathrm{s}$. Because seismic measurements are based on the two-way travel time of the transmitted signals, this uncertainty may result in calculated depth errors of up to 16 feet at 100-foot ranges (distances from the sonar). Actual uncertainty for this project is likely substantially less, and might reasonably be estimated as $+/-10$ feet.

Survey data were interpreted and the character of acoustic basement determined given the potential limitations on data quality listed above. Survey lines in Area "A" that were completed on Day 1 of the survey in 2007, and in the landward third of the survey area provided the best data quality and interpretation with the highest confidence. The outer third of the survey area produced lines with a slightly lower confidence due to building seas later in the day. The middle third of the survey produced lines of a lesser data quality due to interference of the seafloor multiple and its occurrence at approximately the same depth as interpreted acoustic basement reflectors in the inner and outer thirds of the survey area. Data collected on Days 2 and 3 in 2007 were of a lesser quality due to an increased sea state. Data quality on the May 2008 seismic survey was only minimally impacted by sea state. 


\subsection{Magnetic Mapping}

The magnetic survey data identified interesting wide-area patterns associated with geological formations and processes. These features included a pair of northerly oriented linear anomalies with magnetism approximately 1,000 Gamma above local background (see Figures 23 and 24). A non-linear anomaly was located to the southwest of Harding Ledge (Figures 23, 23A and 24).

The location and magnitude of digitized magnetic anomalies are reported in Table 1 and depicted on Figures 23 and 24. Forty-eight anomalies were digitized. The vast majority of these anomalies were negative monopolar (MP-), presumably due to distance from the sensor. Most of the anomalies did not appear to be associated with surficial side scan sonar features. Exceptions are a large MP- anomaly in Area "B” (see Figure 24) and the linear sonar contact identified on Cable Route 4 (see Figure 15A). The latter feature is co-located with two dipolar magnetic anomalies and one monopolar anomalies (Anomalies 38, 39 and 42 - Table 1). Some anomalies appear to be associated with side scan sonar features thought to be lobster gear (e.g., Anomaly 3 - Table 1).

The magnetic contour maps are useful for the identification of very large ferrous objects and geological features. However, these maps are unreliable indicators of the presence of smaller ferrous debris in Areas “A”, “B”, and "C" due to the rather wide spacing of survey transects and concomitant large grid size used for interpolation and contouring (50 ft grid nodes). The survey data does not indicate the presence of large man-made structures (e.g., shipwrecks) within the survey area. Smaller ferrous debris or objects may be present at or near the sediment surface in several portions of the survey area.

\subsection{CONCLUSIONS AND RECOMMENDATIONS}

The hydrographic and geophysical surveys have provided the Hull Offshore Wind Farm project team with information needed to assist with the selection of potential Wind Turbine Generator locations and Cable Routes. Preliminary maps and data were created and delivered at the end of each survey day in August 2007, and the survey data subsequently delivered with a September 
2007 Field Summary Report. In addition, interim 2007 and 2008 data products showing select Boomer profiles at the proposed boring locations were delivered to GZA and ESS to assist with the selection of appropriate locations for exploratory vibracores and borings.

The geophysical data products in this report describe the surface and subsurface characteristics of the offshore survey area and provide the highest resolution data possible given the constraints of the specified survey design and sea state. The vibracore penetration depth generally agreed with the "shallow" sub-bottom data and provided confirmation of sand substrate for the side-scan interpretation. The logged boring data from B-4 and B-5 generally support the "deep" Boomer seismic reflection data interpretation, however, additional borings in areas of interest near the proposed WTG locations would increase the confidence of the geophysical data interpretations. A towed video survey in the vicinity of the selected WTG locations and southern Cable Routes will be conducted in August 2008 by CR and ESS. We suggest that video observations generated during this September survey would allow refinement of the side scan sonar data interpretation.

\subsection{REFERENCES}

Ackerman, S.D., B. Butman, W.A. Barnhardt, W.W. Danforth and J.M. Crocker. 2006. HighResolution Geologic Mapping of the Inner Continental Shelf: Boston Harbor and Approaches, Massachusetts. U.S. Geological Survey Open-File Report 2006-1008.

C-T. Chen and F. J. Millero. 1977. Speed of Sound in Seawater at High Pressures. J. Acoustic Soc. Am., 32(10), page 1357.

US ACOE. 2002. Engineering and Design Hydrographic Surveying. EM1110-2-1003. Ch. 3 Corps Accuracy Standards, Quality Control, and Quality Assurance Requirements. Washington, D.C.: pg 3-1. 


\section{PHOTOGRAPHS}




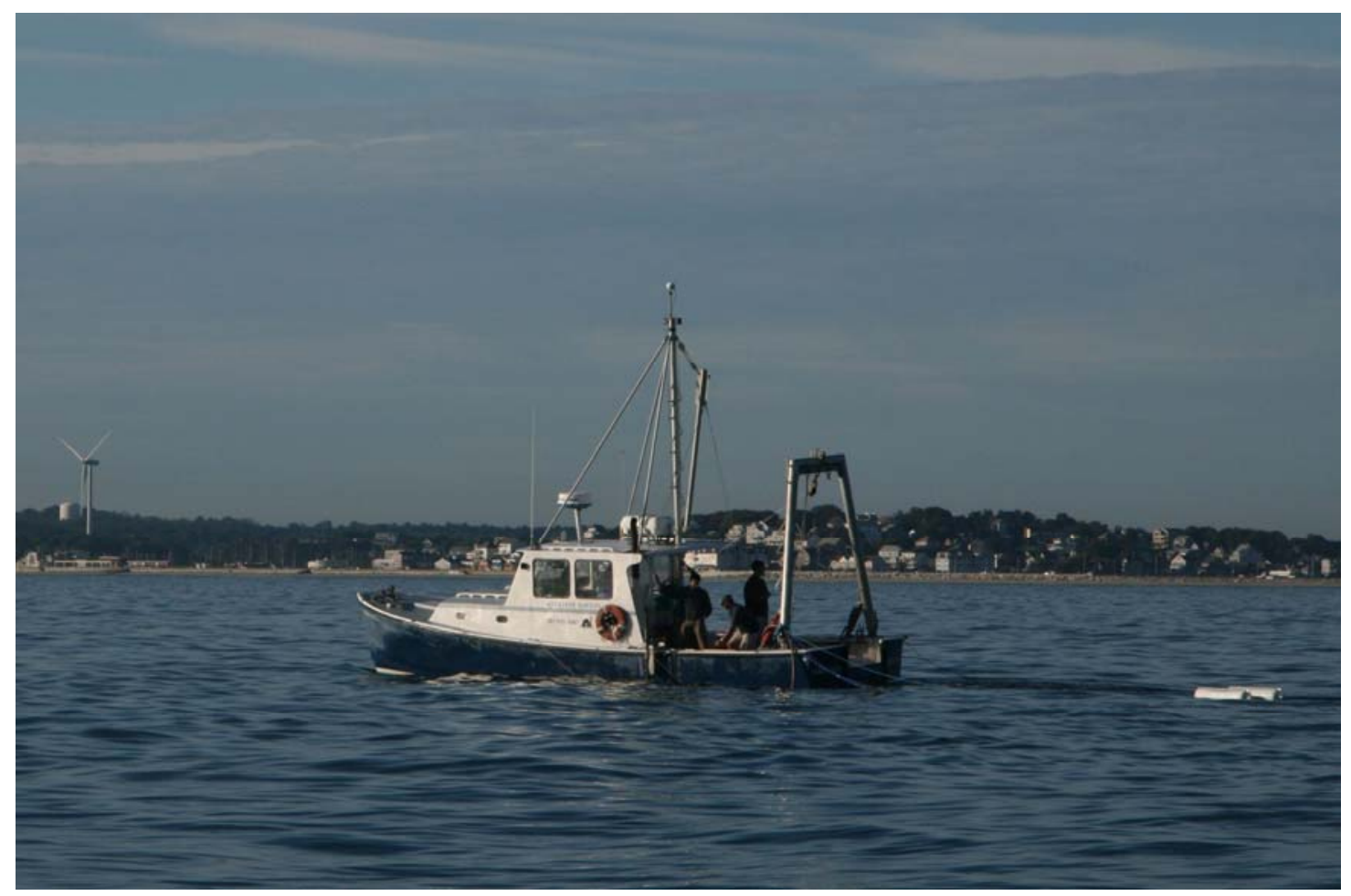

Photograph 1 R/V Sakonnet towing a sub-bottom profiler on the Geophysical Survey

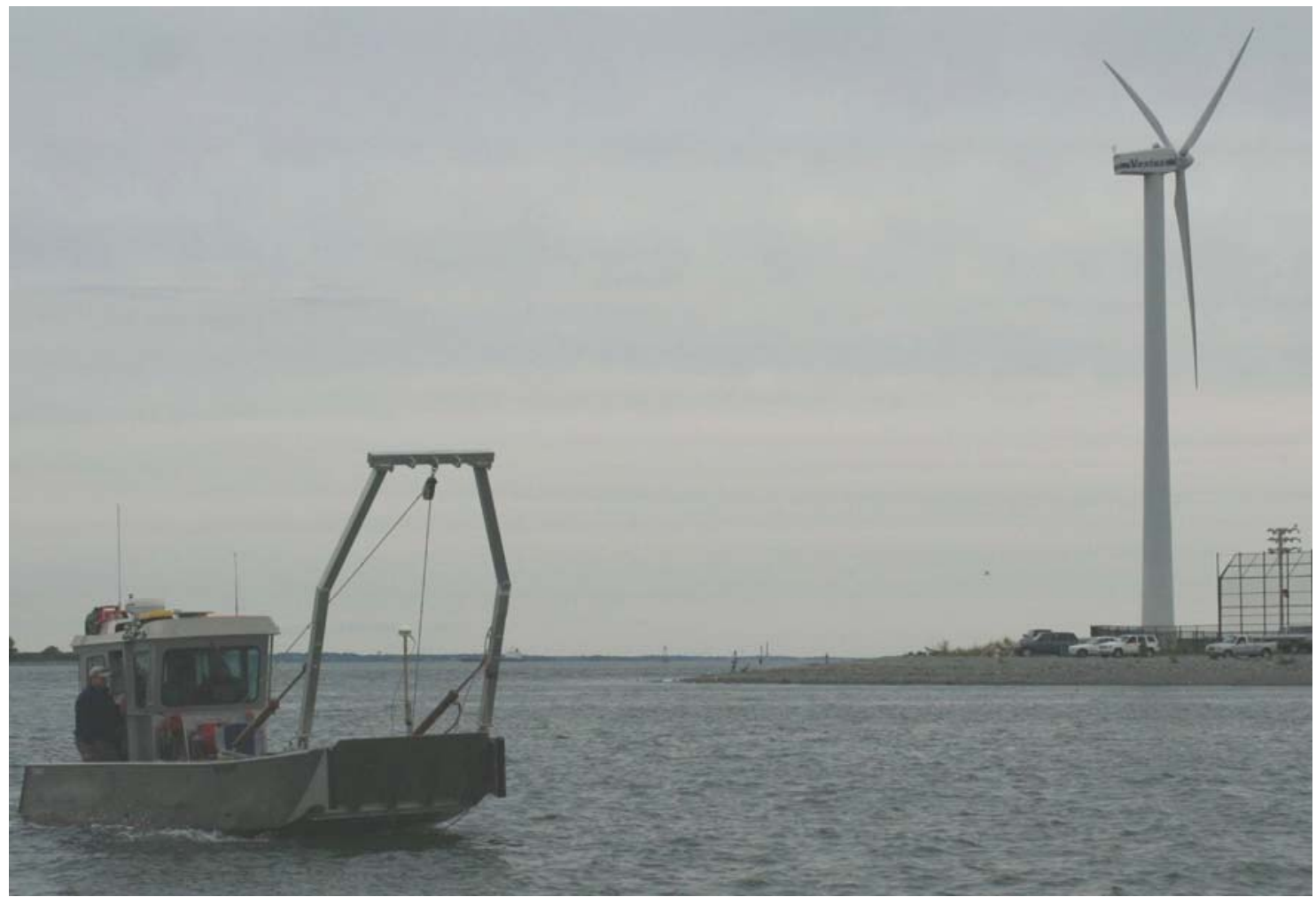

Photograph 2 R/V Lophius collected bathymetric, side scan sonar, and magnetic data 


\section{TABLES}


TABLE 1

MAGNETOMETER ANOMALIES HULL OFFSHORE WIND PROJECT

\begin{tabular}{|c|c|c|c|c|c|c|c|}
\hline ID & TYPE $^{1}$ & MAGNITUDE (GAMMA) $^{2}$ & $\mathrm{X}$ & $\bar{Y}$ & GAMMA & DURATION (FEET) $^{3}$ & FILE \\
\hline 1 & MP- & 27 & 834892.7 & 2929522 & 52719.1 & 15 & 007_0845 \\
\hline 2 & MP- & 14 & 833103.8 & 2933007 & 52784.7 & 24 & 009_0912 \\
\hline 3 & MP- & 120 & 831369.9 & 2935886 & 52678.4 & 21 & 009_0912 \\
\hline 4 & $\mathrm{DP}$ & 8 & 833646.3 & 2932916 & 52794.7 & 175 & 011_0940 \\
\hline 5 & MP- & 30 & 835506.7 & 2929973 & 52728.3 & 23 & 011_0940 \\
\hline 6 & MP- & 37 & 834136.6 & 2933662 & 52763.4 & 21 & 015_1101 \\
\hline 7 & MP- & 79 & 834952.7 & 2933065 & 52719.3 & 22 & $017 \_1122$ \\
\hline 8 & MP- & 25 & 837000.9 & 2930582 & 52769.3 & 23 & 019_1205 \\
\hline 9 & MP- & 25 & 829910.6 & 2937347 & 52775.2 & 23 & 044_1256 \\
\hline 10 & MP- & 14 & 829348.2 & 2936033 & 52823.1 & 42 & 001_1309 \\
\hline 11 & DP & 5 & 832346 & 2931221 & 52798.4 & 70 & 001_1309 \\
\hline 12 & DP & 5 & 832593.7 & 2931173 & 52793.2 & 127 & $002 \_1340$ \\
\hline 13 & $\mathrm{MP+}$ & 12 & 830019.8 & 2935345 & 52804.2 & 120 & $002 \_1340$ \\
\hline 14 & MP- & 100 & 832690 & 2931843 & 52699.5 & 24 & 004_1405 \\
\hline 15 & $\mathrm{DP}$ & 3 & 834842.6 & 2929203 & 52762.2 & 160 & 006_1432 \\
\hline 16 & MP- & 84 & 830303.5 & 2937149 & 52716.1 & 22 & 008_1457 \\
\hline 17 & MP- & 30 & 835305.7 & 2932903 & 52761.2 & 25 & 018_0933 \\
\hline 18 & MP- & 290 & 833595.8 & 2935638 & 52510.4 & 24 & 018_0933 \\
\hline 19 & MP- & 125 & 834772.4 & 2933304 & 52673.6 & 21 & 048 1107 \\
\hline 20 & MP- & 150 & 839734.4 & 2934663 & 52647.1 & 24 & 049_1133 \\
\hline 21 & MP- & 435 & 838863.7 & 2934110 & 52365.2 & 26 & 049_1133 \\
\hline 22 & DP & 8 & 835909.7 & 2930532 & 52772.1 & 48 & 050_1155 \\
\hline 23 & DP & 9 & 835865.2 & 2930593 & 52774.7 & 5 & 050_1155 \\
\hline 24 & MP- & 27 & 836385.8 & 2929007 & 52765.1 & 29 & $001 \_1225$ \\
\hline 25 & MP- & 25 & 839265.2 & 2933170 & 52775.3 & 23 & $003-1316$ \\
\hline 26 & MP- & 28 & 840352.8 & 2931437 & 52772 & 23 & $003-1316$ \\
\hline 27 & MP- & 12 & 841352.8 & 2932674 & 52788.1 & 22 & 004_1335 \\
\hline 28 & MP- & 250 & 828361 & 2932024 & 52548.5 & 28 & $003-1444$ \\
\hline 29 & MP- & 35 & 828662.2 & 2932135 & 52765.8 & 29 & 003_1444 \\
\hline 30 & MP- & 250 & 828560.2 & 2931989 & 52547.7 & 25 & 001_1455 \\
\hline 31 & MP- & 25 & 828890.5 & 2932118 & 52774.6 & 46 & 001_1455 \\
\hline 32 & MP- & 40 & 828795.9 & 2932130 & 52760.6 & 21 & 002_1521 \\
\hline 33 & MP- & 370 & 828889.6 & 2932098 & 52429.3 & 30 & 001_1559 \\
\hline 34 & MP- & 104 & 827998.6 & 2931778 & 52696.8 & 28 & 001_1559 \\
\hline 35 & MP. & 115 & 830169.5 & 2933705 & 52686.8 & 17 & 001_0835 \\
\hline 36 & MP. & 60 & 827814.2 & 2933736 & 52731.7 & 22 & 001_0835 \\
\hline 37 & MP- & 130 & 827811.1 & 2933774 & 52687.3 & 25 & 001_0905 \\
\hline 38 & DP & 5 & 829013 & 2933527 & 52778.5 & 134 & 005_0931 \\
\hline 39 & $\mathrm{MP+}$ & 4 & 828865.1 & 2933675 & 52786.5 & 143 & 002_0955 \\
\hline 40 & MP- & 20 & 832410.9 & 2933533 & 52780.9 & 30 & 004_1014 \\
\hline 41 & MP- & 25 & 830145.2 & 2933562 & 52774.1 & 29 & 004_1014 \\
\hline 42 & DP & 6 & 829011.5 & 2933570 & 52773.9 & 173 & 004_1014 \\
\hline 43 & MP- & 83 & 832503.2 & 2933573 & 52713.2 & 28 & 003_1046 \\
\hline 44 & MP- & 30 & 829942.2 & 2935747 & 52740.6 & 26 & 001_1237 \\
\hline 45 & DP & 4 & 825936.9 & 2935154 & 52794.7 & 78 & 004_1248 \\
\hline 46 & DP & 5 & 826073.5 & 2935177 & 52796.9 & 96 & 004_1248 \\
\hline 47 & MP- & 44 & 829912.8 & 2935216 & 52746.8 & 30 & $002 \_1413$ \\
\hline 48 & MP. & 40 & 829518.2 & 2935475 & 52758.4 & 25 & $010 \_1436$ \\
\hline
\end{tabular}

NOTES:

1 Anomalies observed during inspection of magnetic profiles were categorized as dipolar (DP) or positive or negative Monopolar (MP+ and MP-).

2 The magnitude of the anomaly was assessed based on variation from preceding "background" readings.

3 Durations approximate based on inspection of profile data. The sample rate was $1 \mathrm{~Hz}$, resulting in one measurement every 5 to 8 feet along each line.

$4 \quad$ This list of anomalies may include point outliers associated with instrument performance in rough sea states.

5 Coordinates are Massachusetts State Plane (Mainland), NAD83, US Foot. 


\section{FIGURES}


FIGURE 1

SURVEY DESIGN

HULL OFFSHORE WIND PROJECT

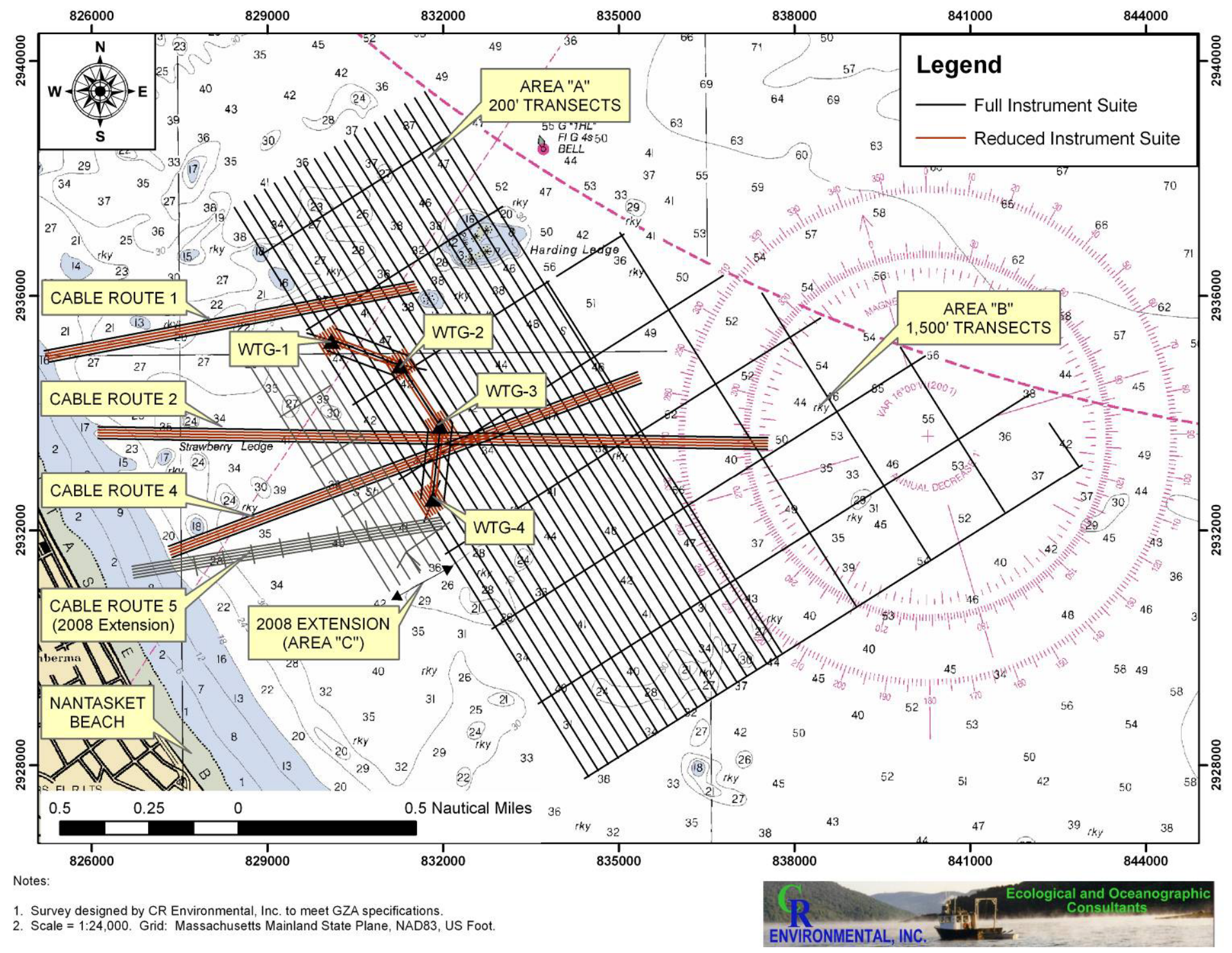


FIGURE 2

BATHYMETRIC CONTOUR MAP

HULL OFFSHORE WIND PROJECT

2.0 Foot Contour Interval, MLLW

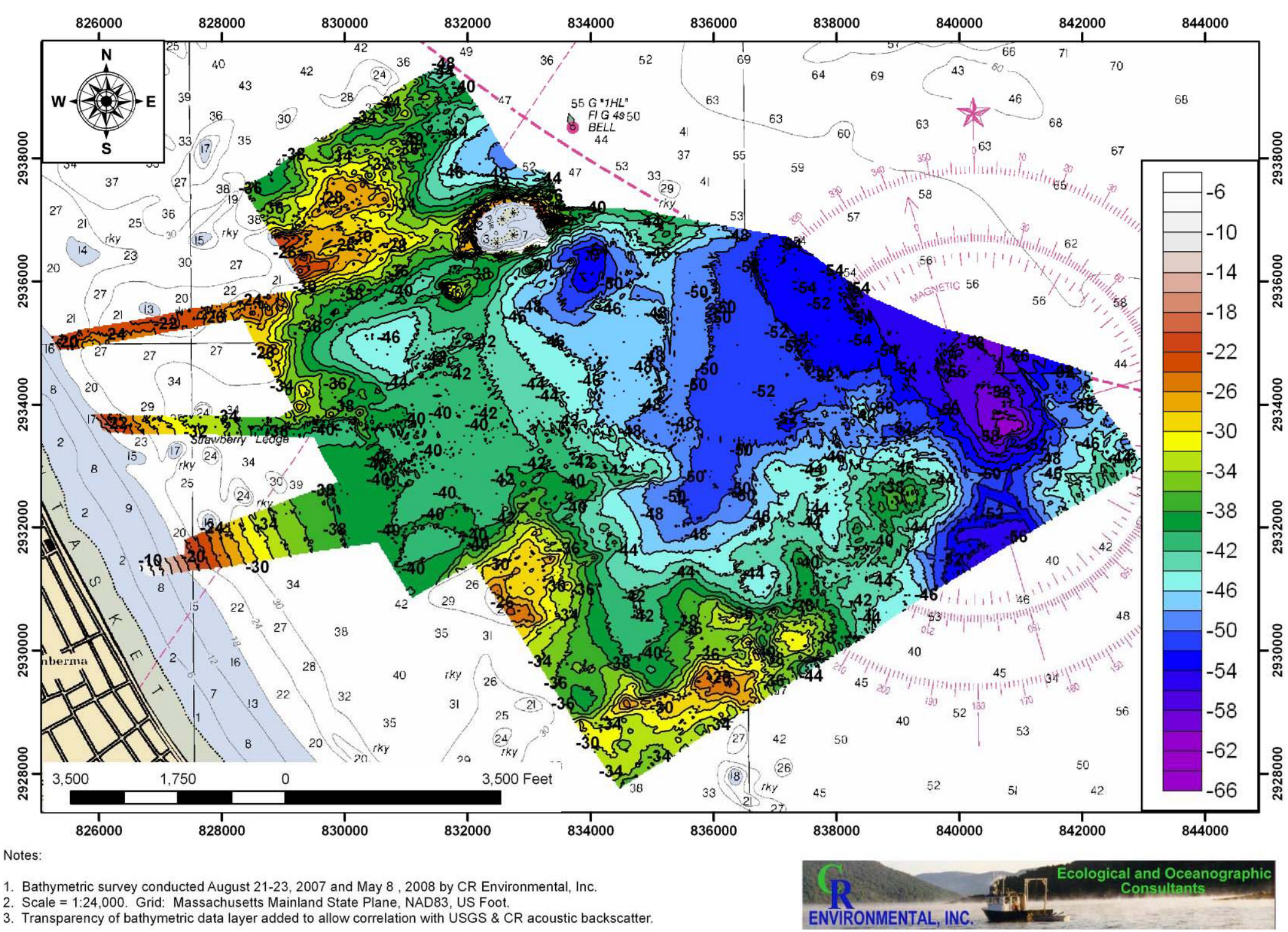


FIGURE 3

SIDE SCAN SONAR MOSAIC

\section{HULL OFFSHORE WIND PROJECT}

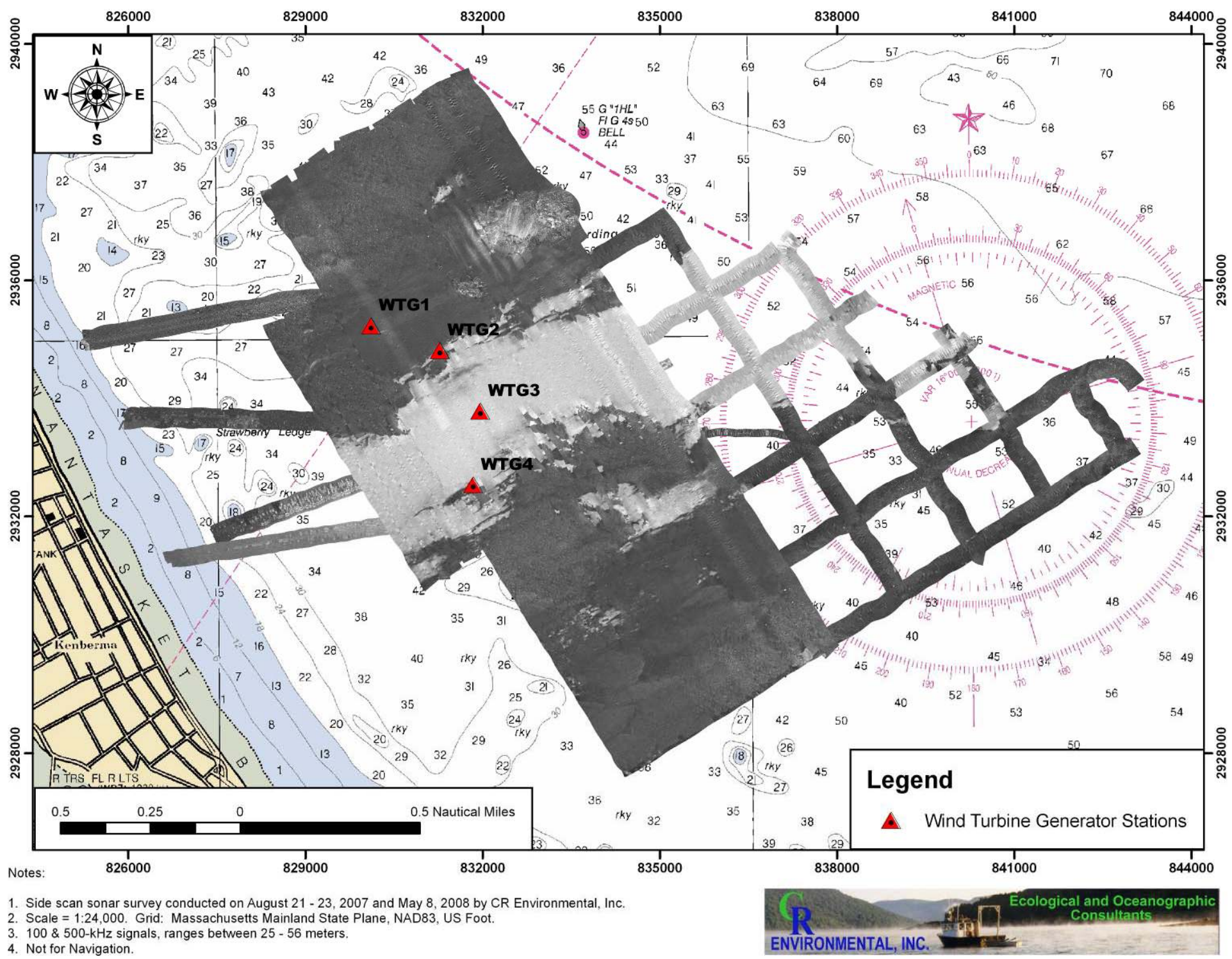


FIGURE 4

SIDE SCAN SONAR ASSESSMENT OF LIKELY SUBSTRATE TYPES HULL OFFSHORE WIND PROJECT

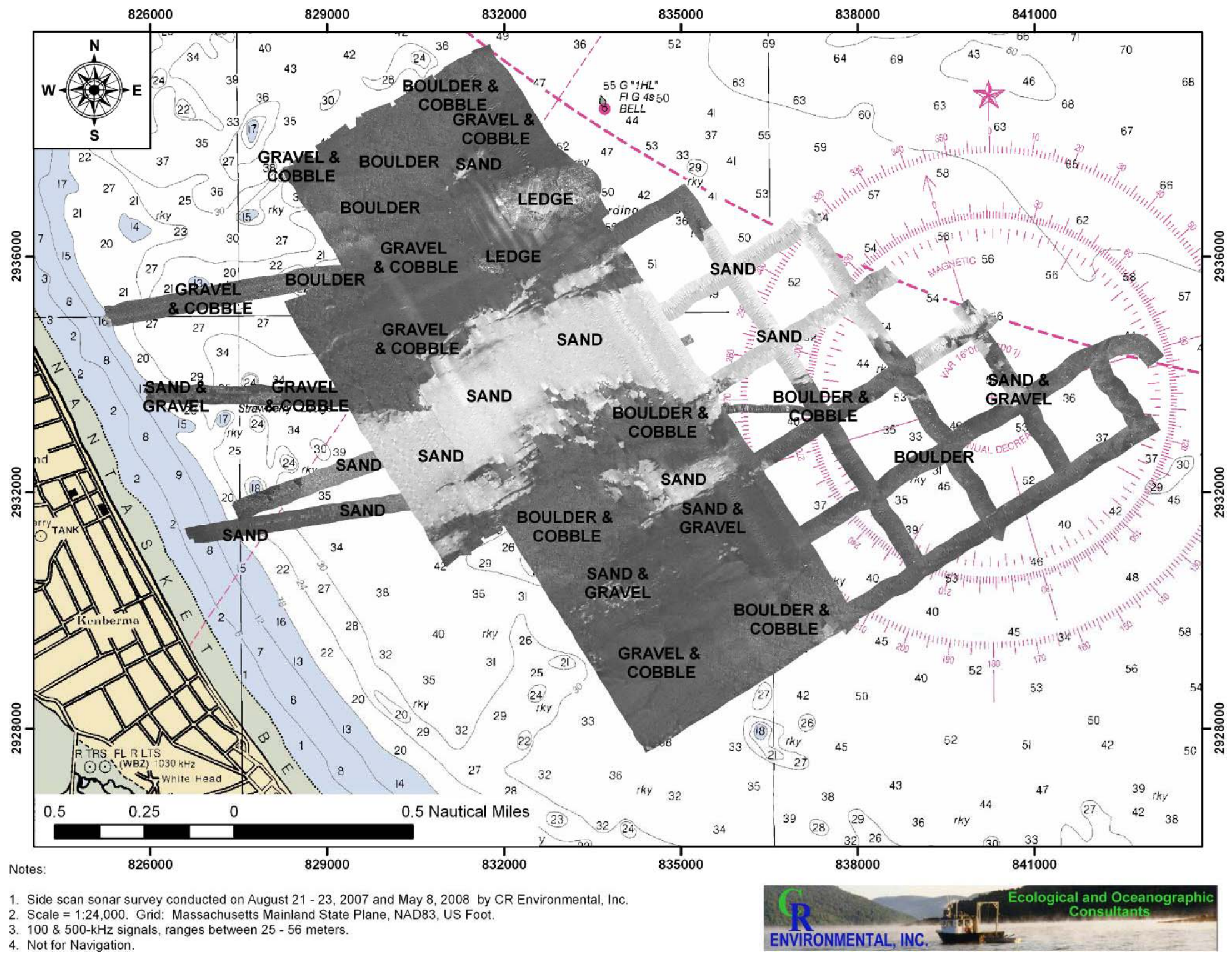


FIGURE 5

SIDE SCAN SONAR MOSAIC OF WTG ALIGNMENT HULL OFFSHORE WIND PROJECT

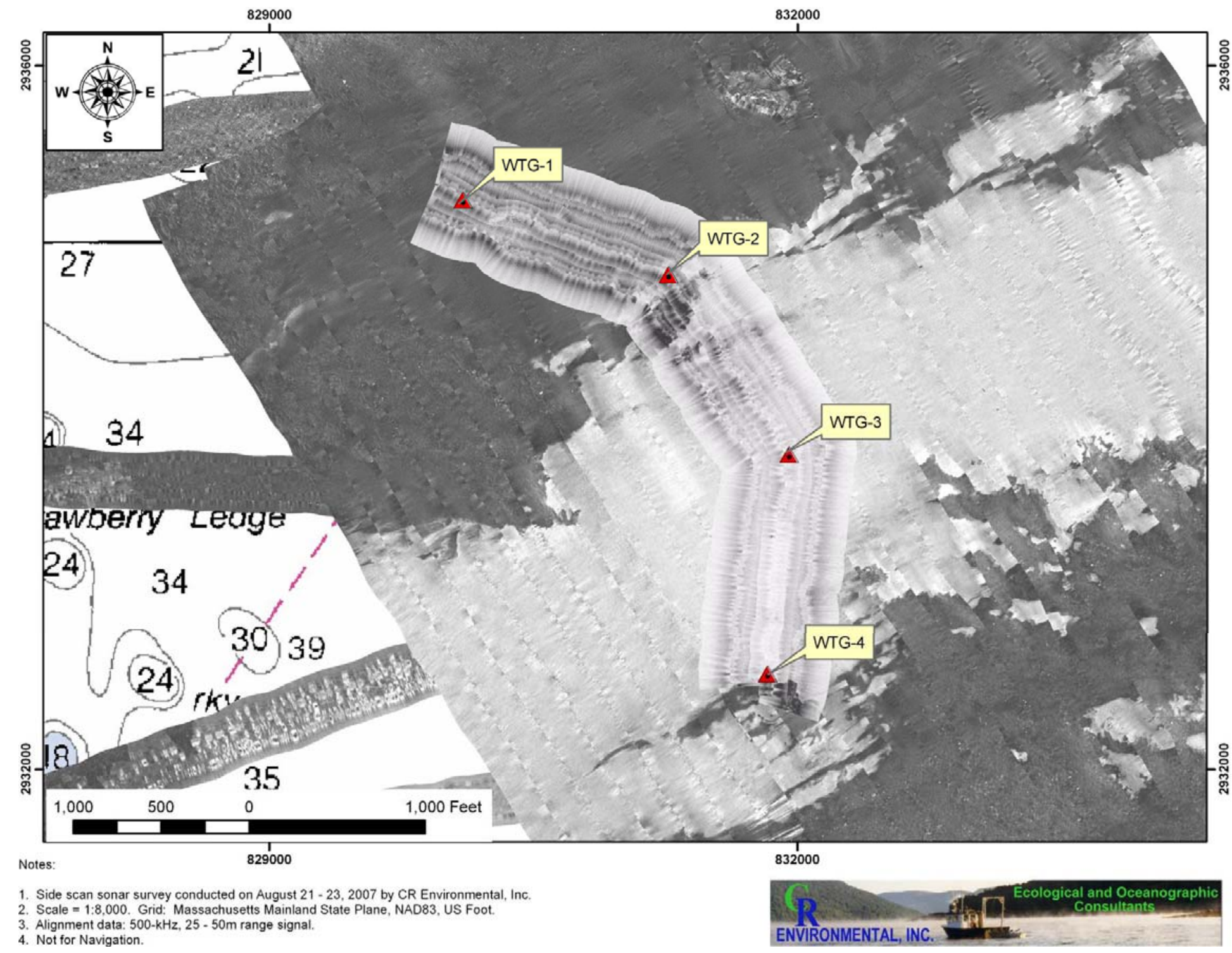


FIGURE 6

SIDE SCAN SONAR MOSAIC OF WTG-1 HULL OFFSHORE WIND PROJECT

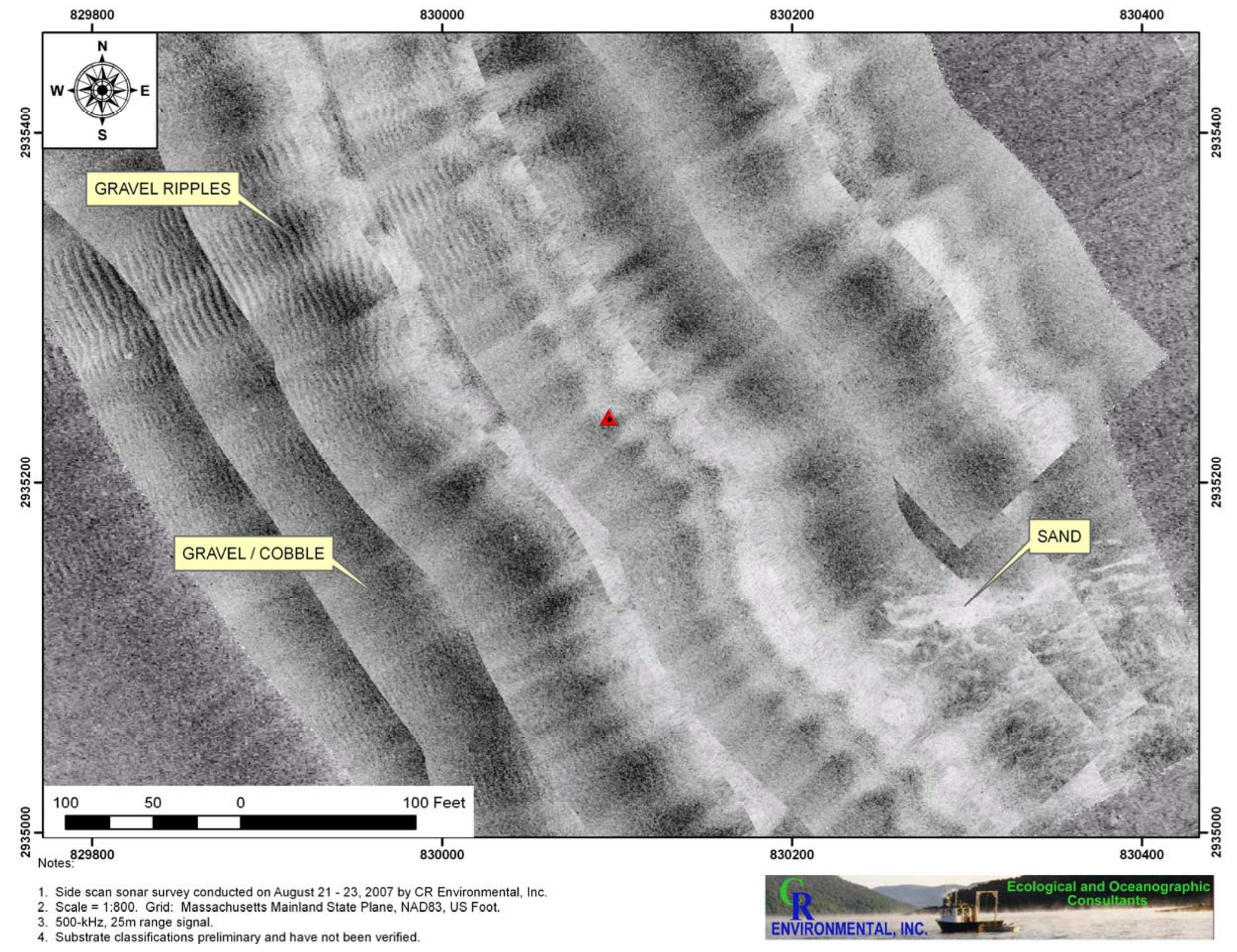


FIGURE 7

SIDE SCAN SONAR MOSAIC OF WTG-2 HULL OFFSHORE WIND PROJECT

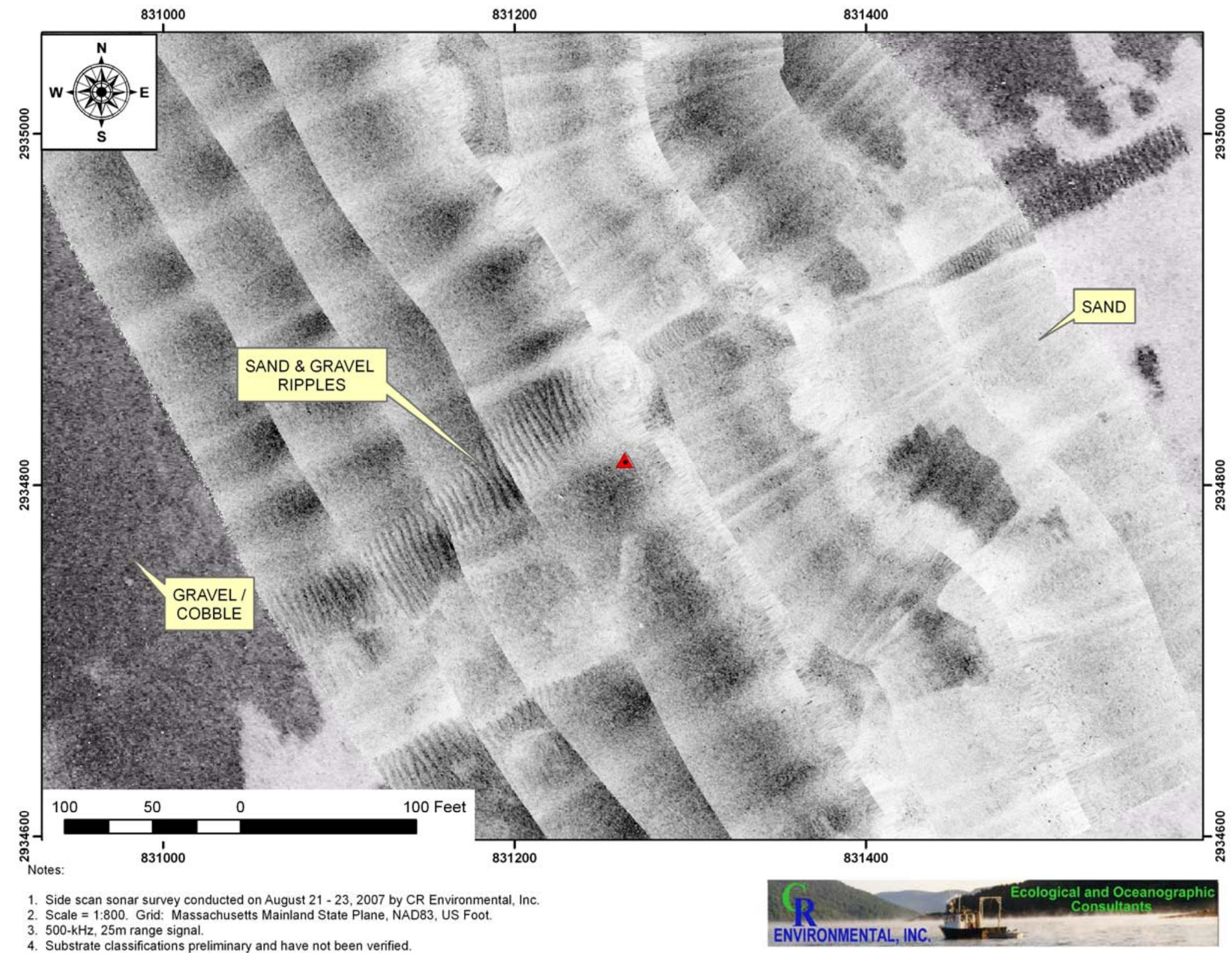


FIGURE 8

SIDE SCAN SONAR MOSAIC OF WTG-3

HULL OFFSHORE WIND PROJECT

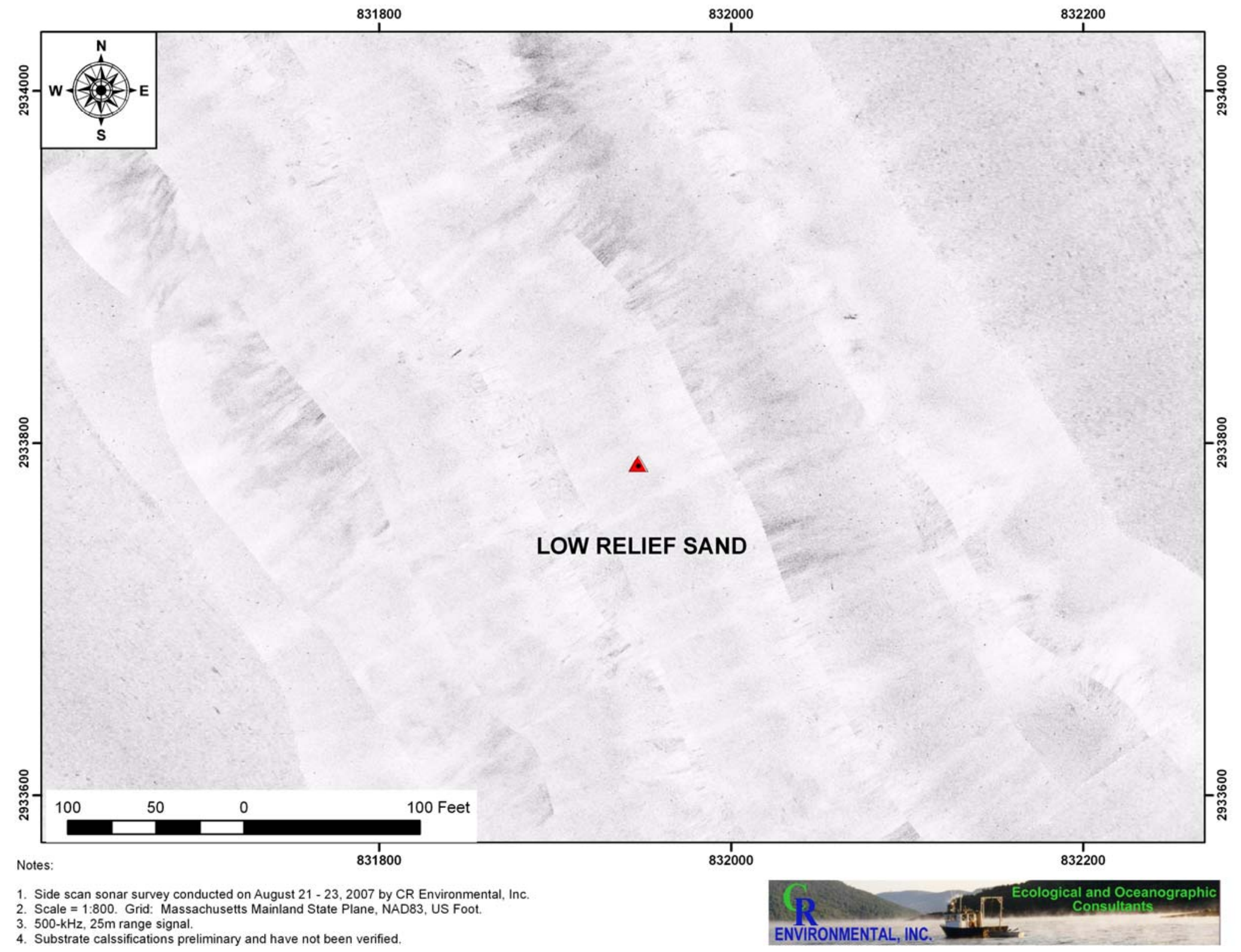


FIGURE 9

SIDE SCAN SONAR MOSAIC OF WTG-4 HULL OFFSHORE WIND PROJECT

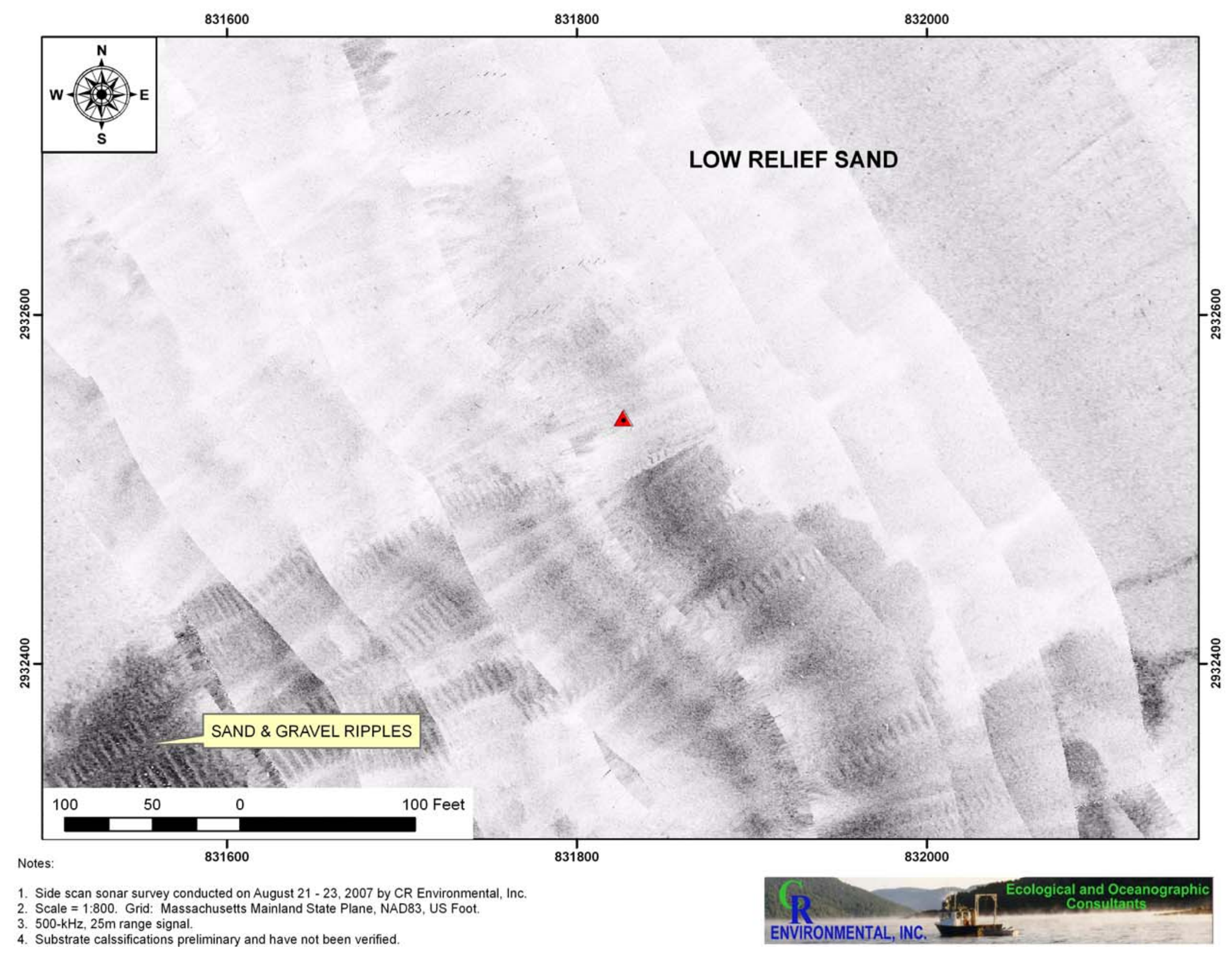


FIGURE 10

SIDE SCAN SONAR MOSAIC OF CABLE ROUTE NO. 1

HULL OFFSHORE WIND PROJECT

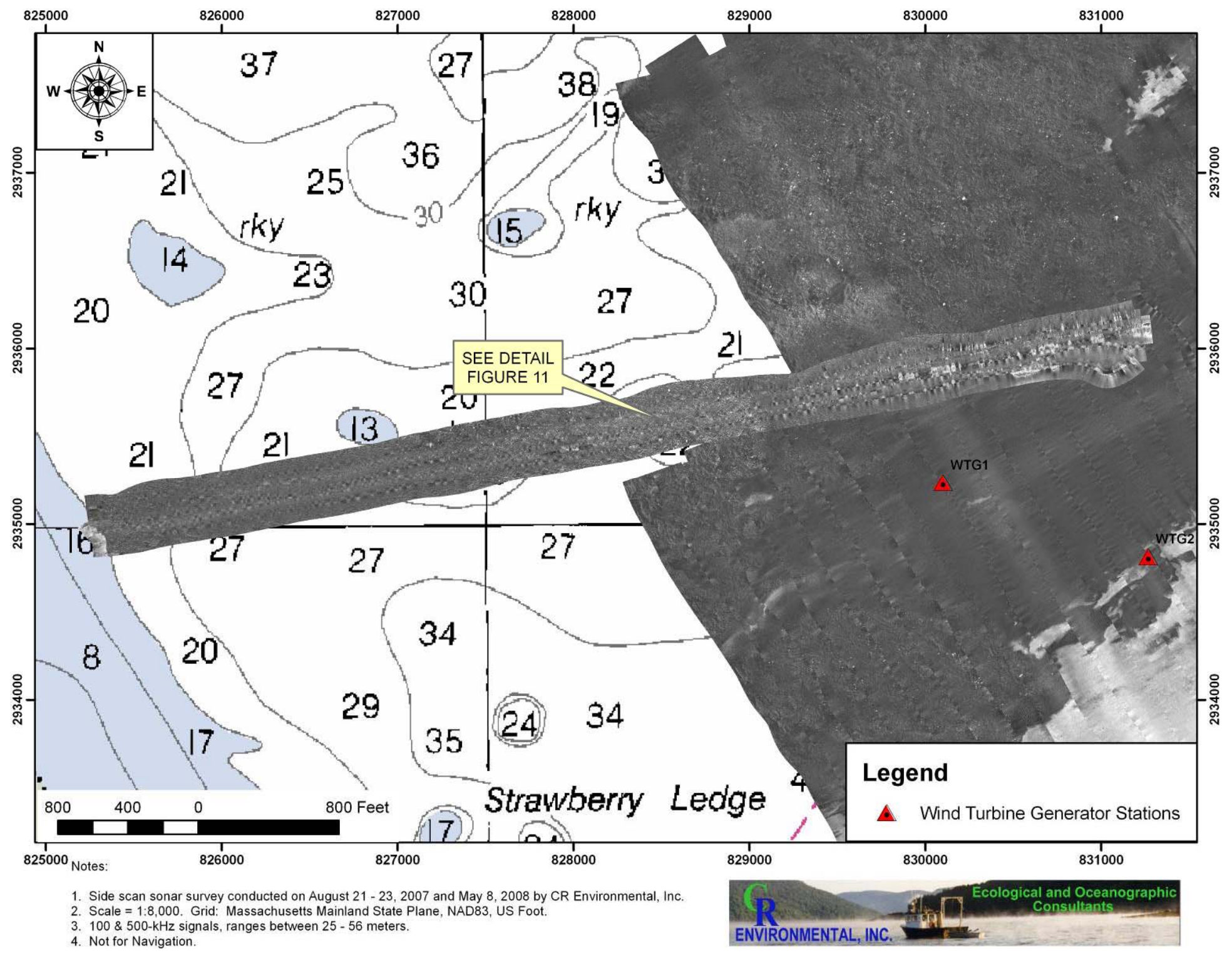


FIGURE 11

DETAIL - SIDE SCAN SONAR MOSAIC OF CABLE ROUTE NO. 1 HULL OFFSHORE WIND PROJECT

(Inverted Gray Scale)

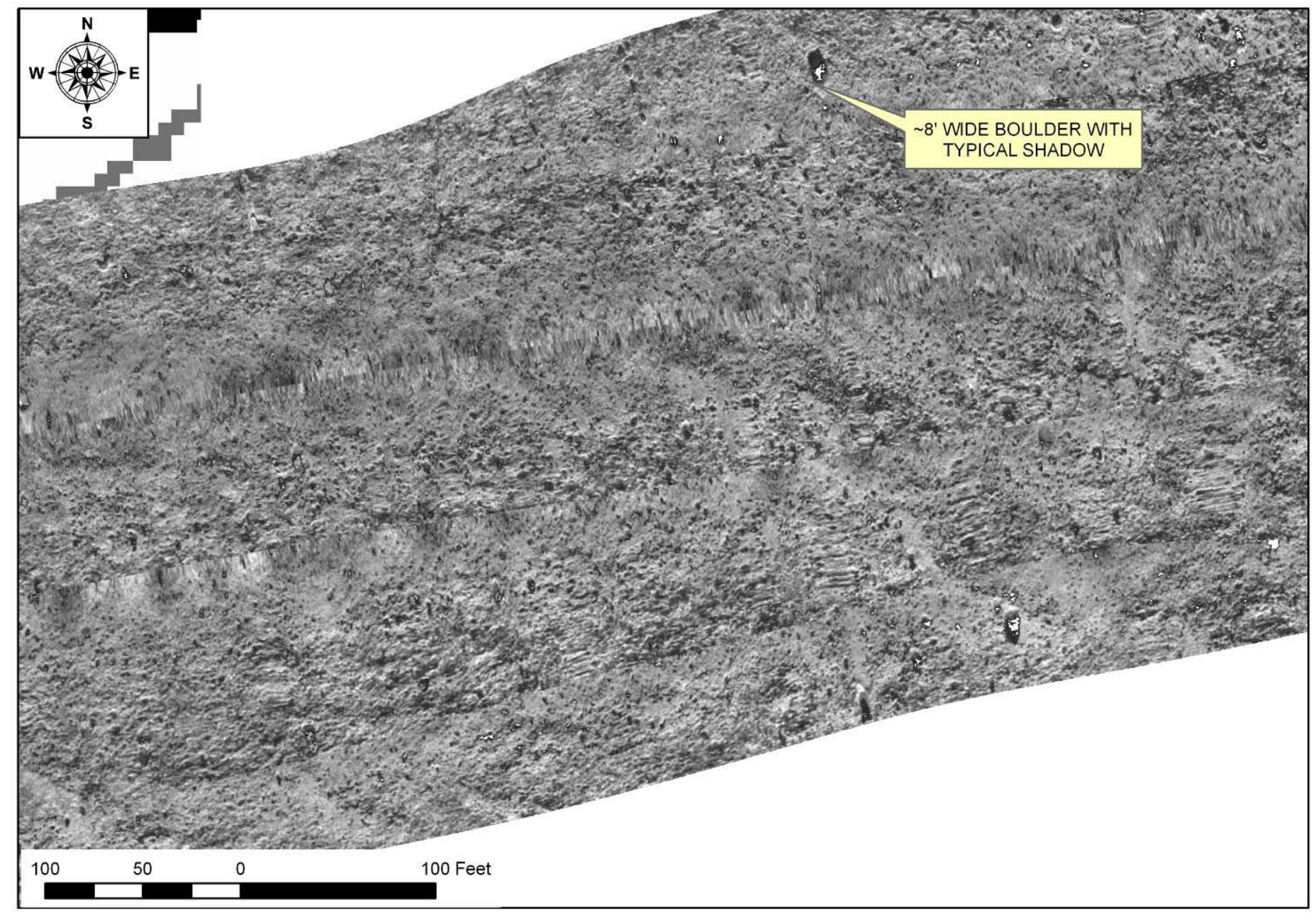

Notes:

1. Side scan sonar survey conducted on August $21-23,2007$ by CR Environmental, Inc. 2. Scale $=1: 800$. Grid: Massachusetts Mainland State Plane, NAD83, US Foot.

3. $500-\mathrm{kH}$ signal, ranges between $25-56$ melers

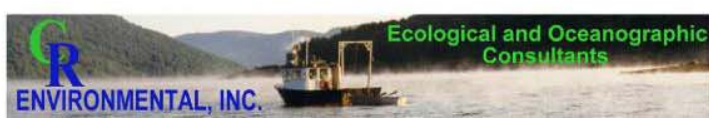


FIGURE 12

SIDE SCAN SONAR MOSAIC OF CABLE ROUTE NO. 2 HULL OFFSHORE WIND PROJECT

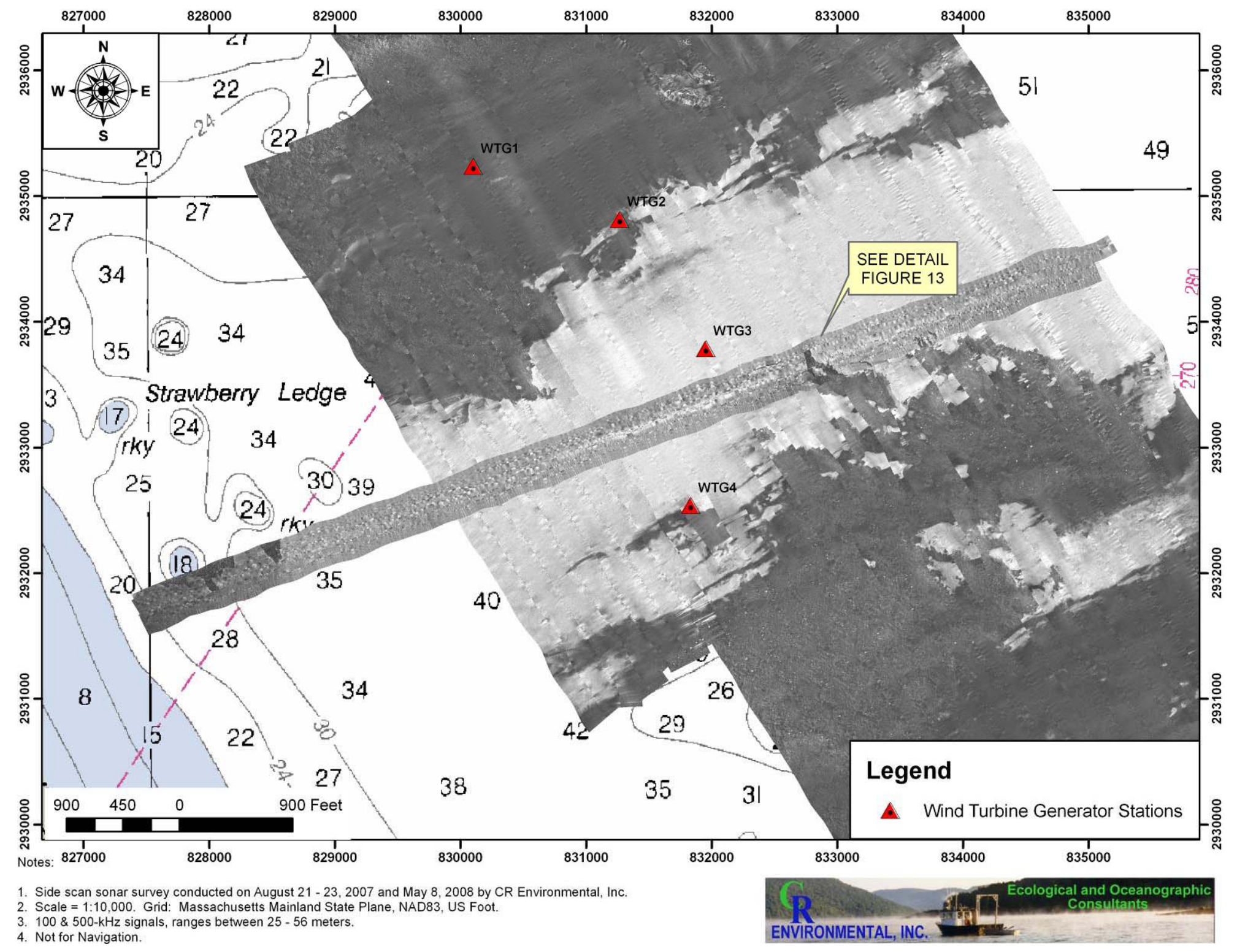


FIGURE 13

DETAIL - SIDE SCAN SONAR MOSAIC OF CABLE ROUTE NO. 2 HULL OFFSHORE WIND PROJECT

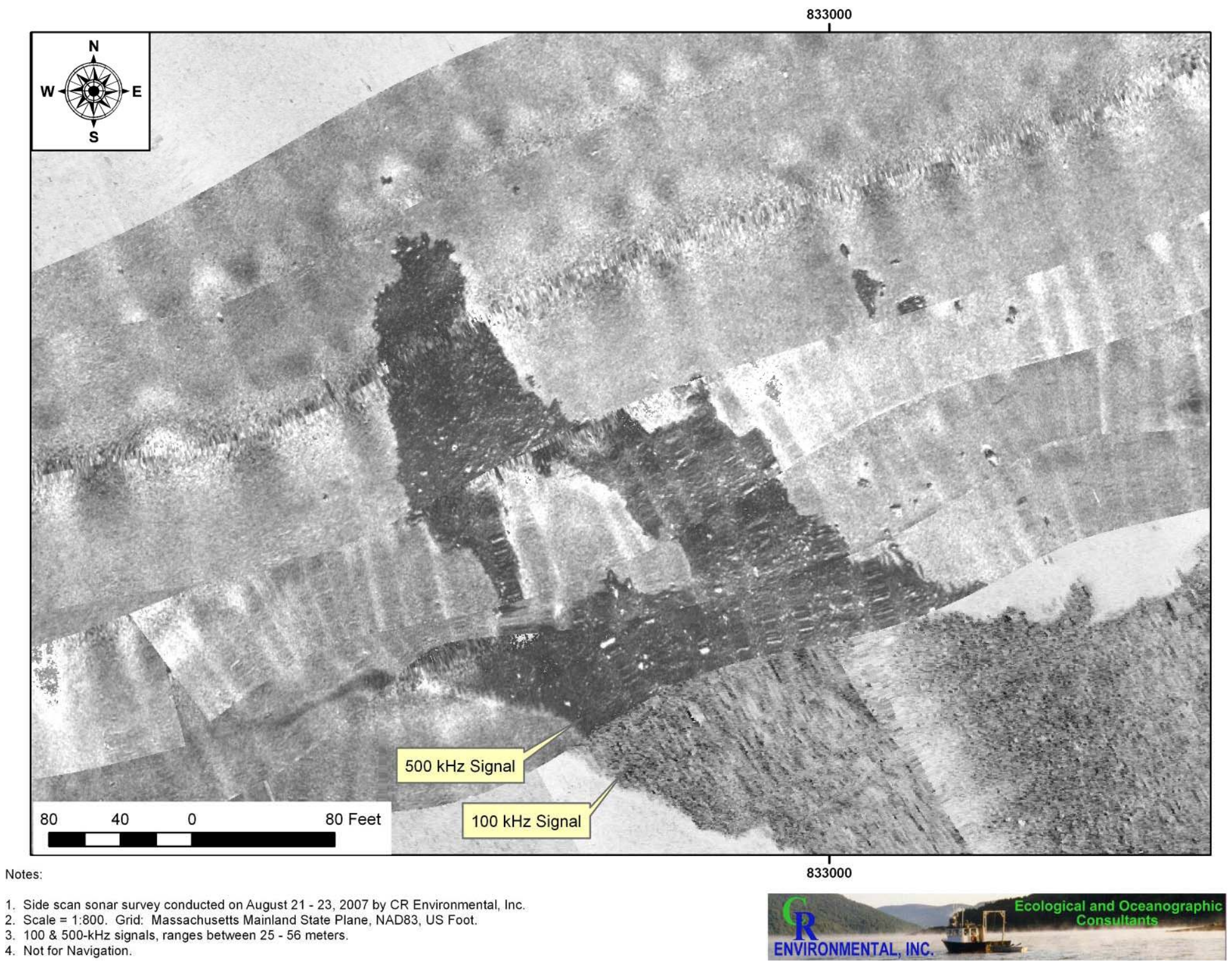


FIGURE 14

SIDE SCAN SONAR MOSAIC OF CABLE ROUTE NO. 4 HULL OFFSHORE WIND PROJECT

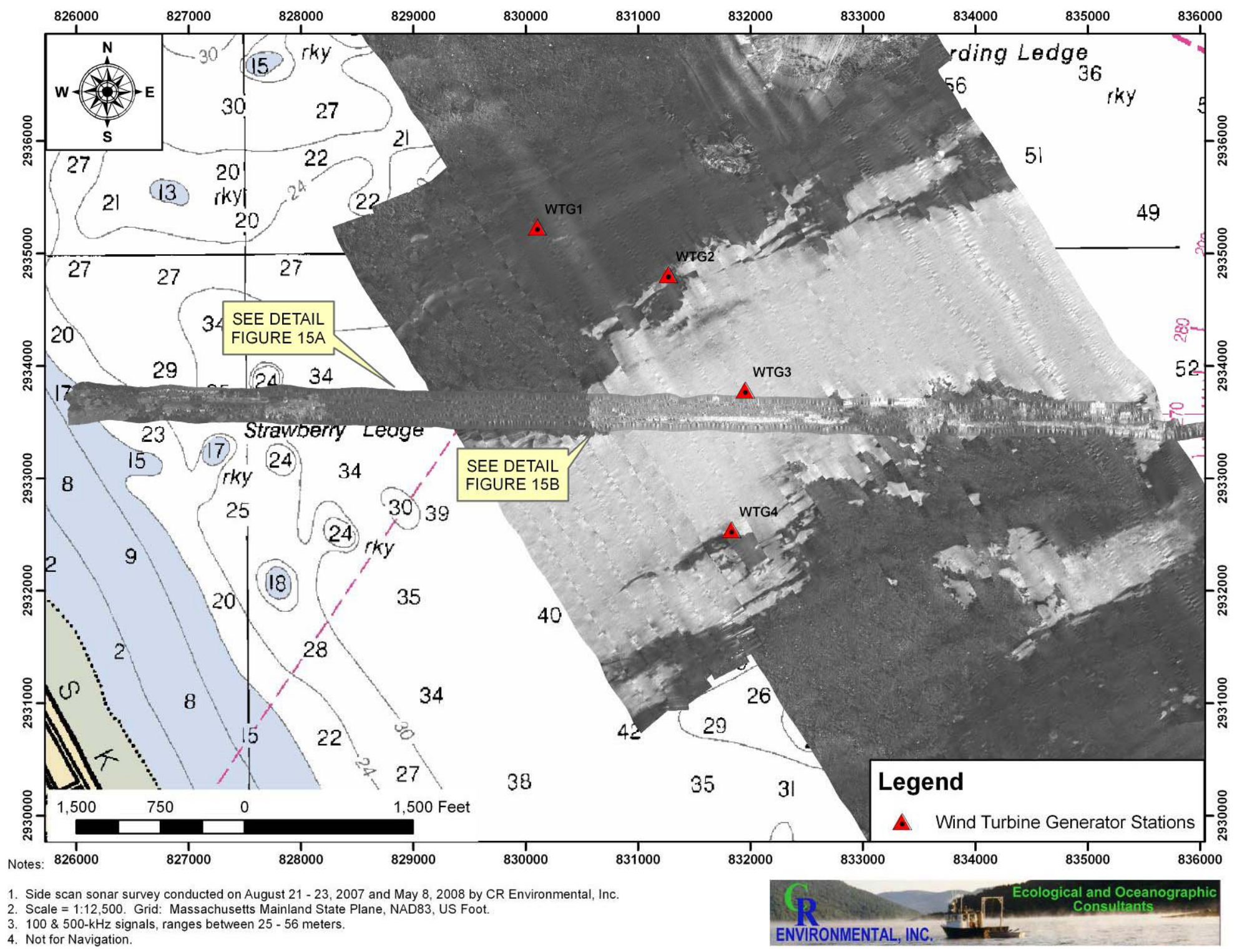


FIGURE 15A

DETAIL 1 - SIDE SCAN SONAR MOSAIC OF CABLE ROUTE NO. 4 HULL OFFSHORE WIND PROJECT

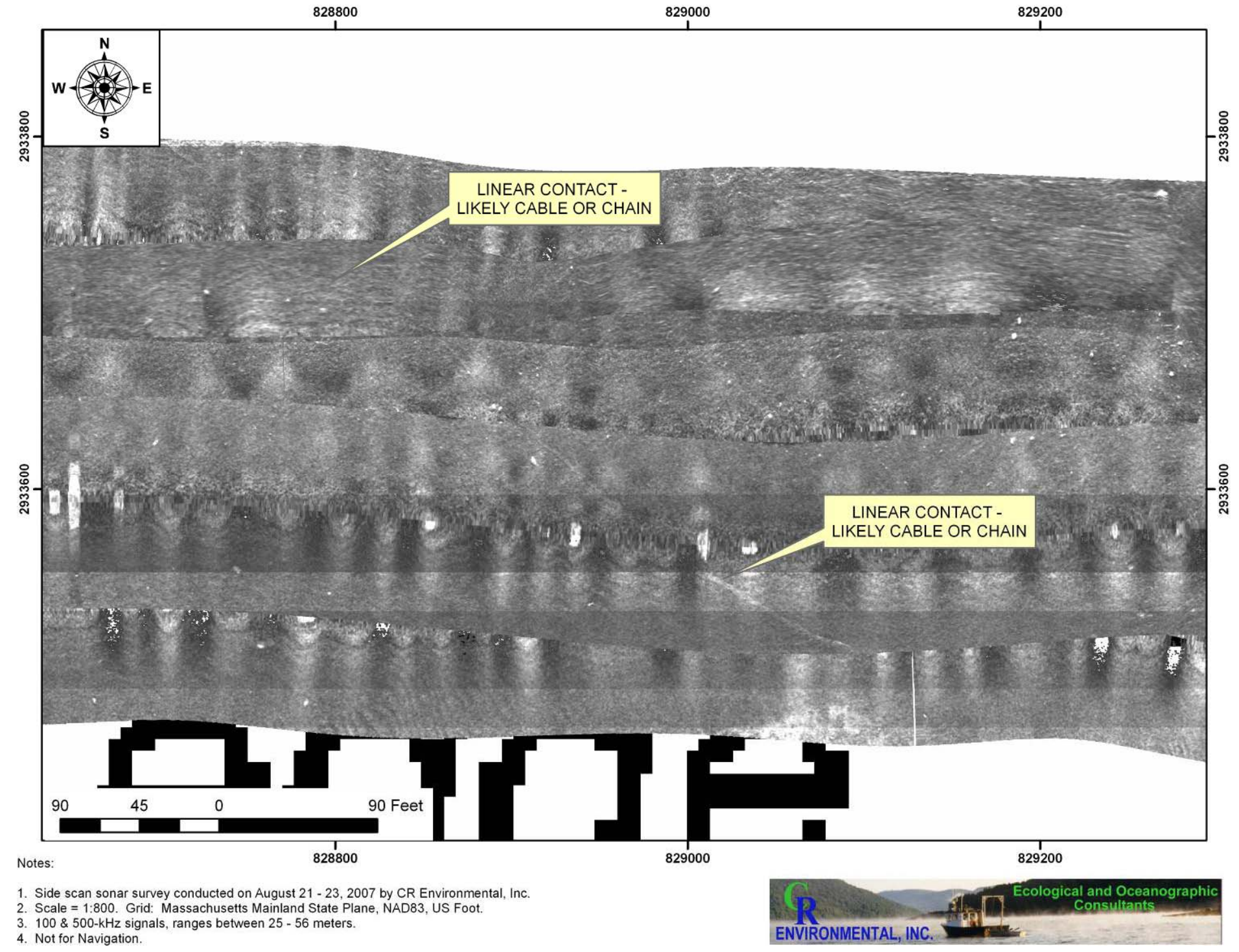


FIGURE 15B

DETAIL 2 - SIDE SCAN SONAR MOSAIC OF CABLE ROUTE NO. 4 HULL OFFSHORE WIND PROJECT

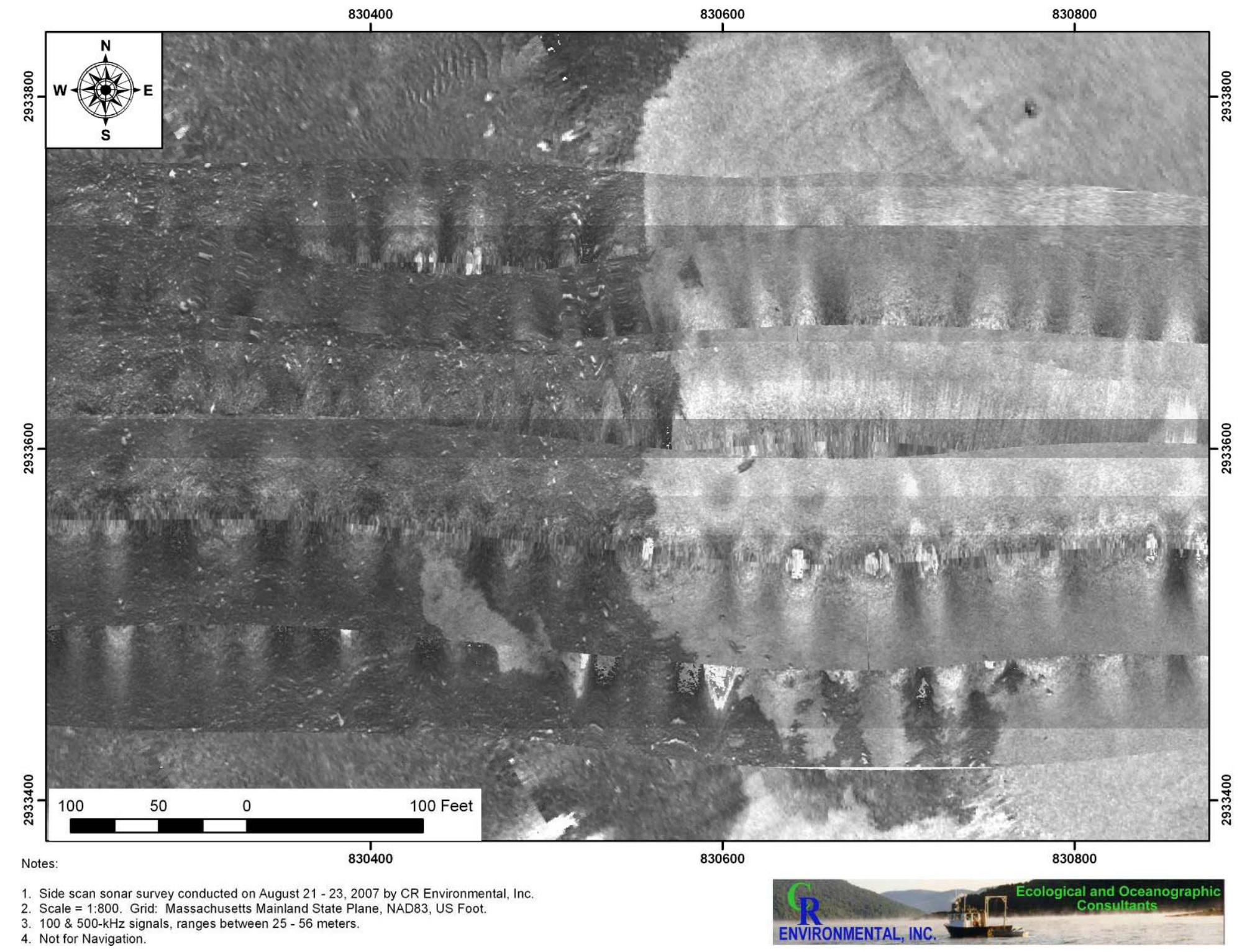


FIGURE 16

SIDE SCAN SONAR MOSAIC OF CABLE ROUTE NO. 5

HULL OFFSHORE WIND PROJECT

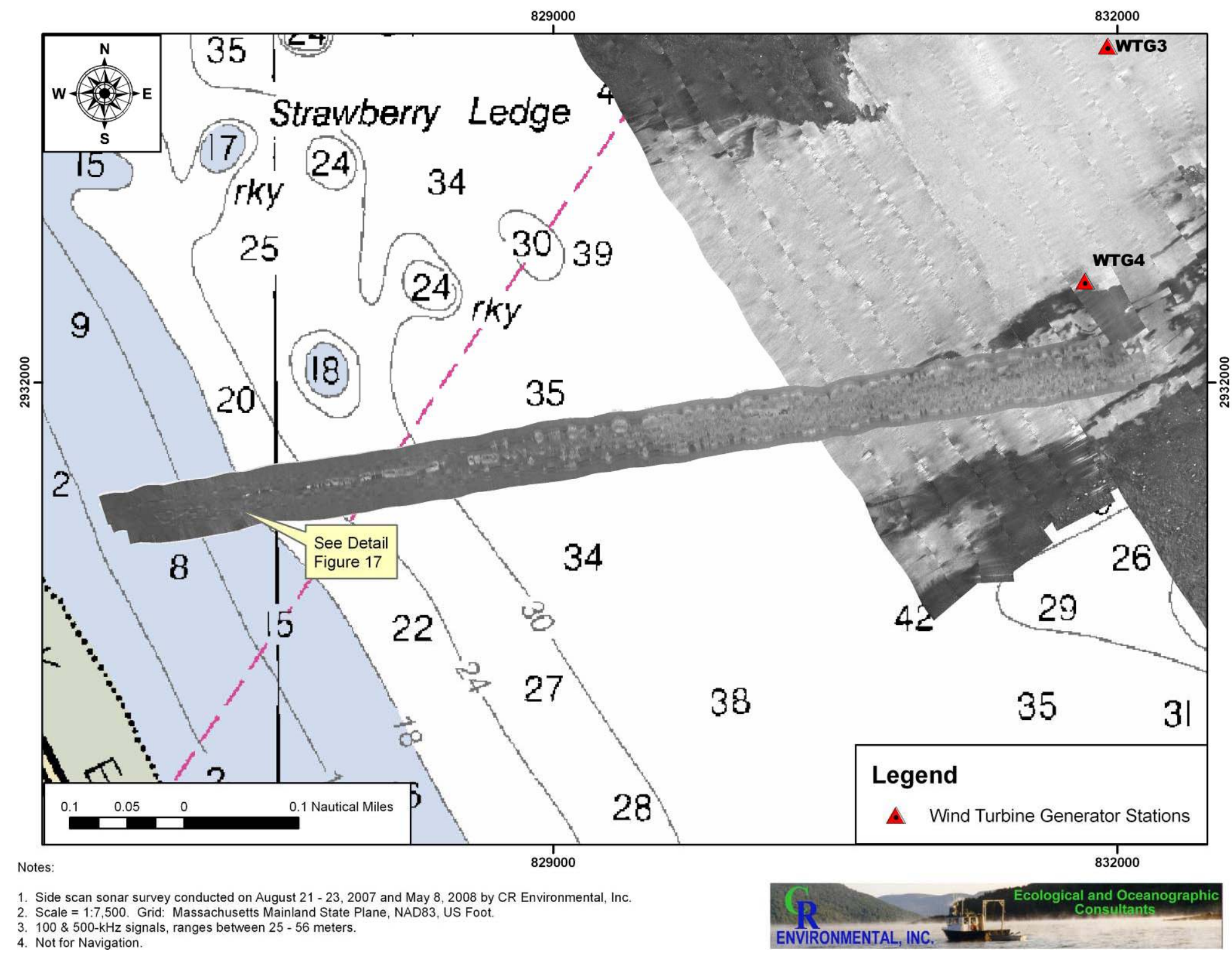


FIGURE 17

DETAIL - SIDE SCAN SONAR MOSAIC OF CABLE ROUTE NO. 5 HULL OFFSHORE WIND PROJECT

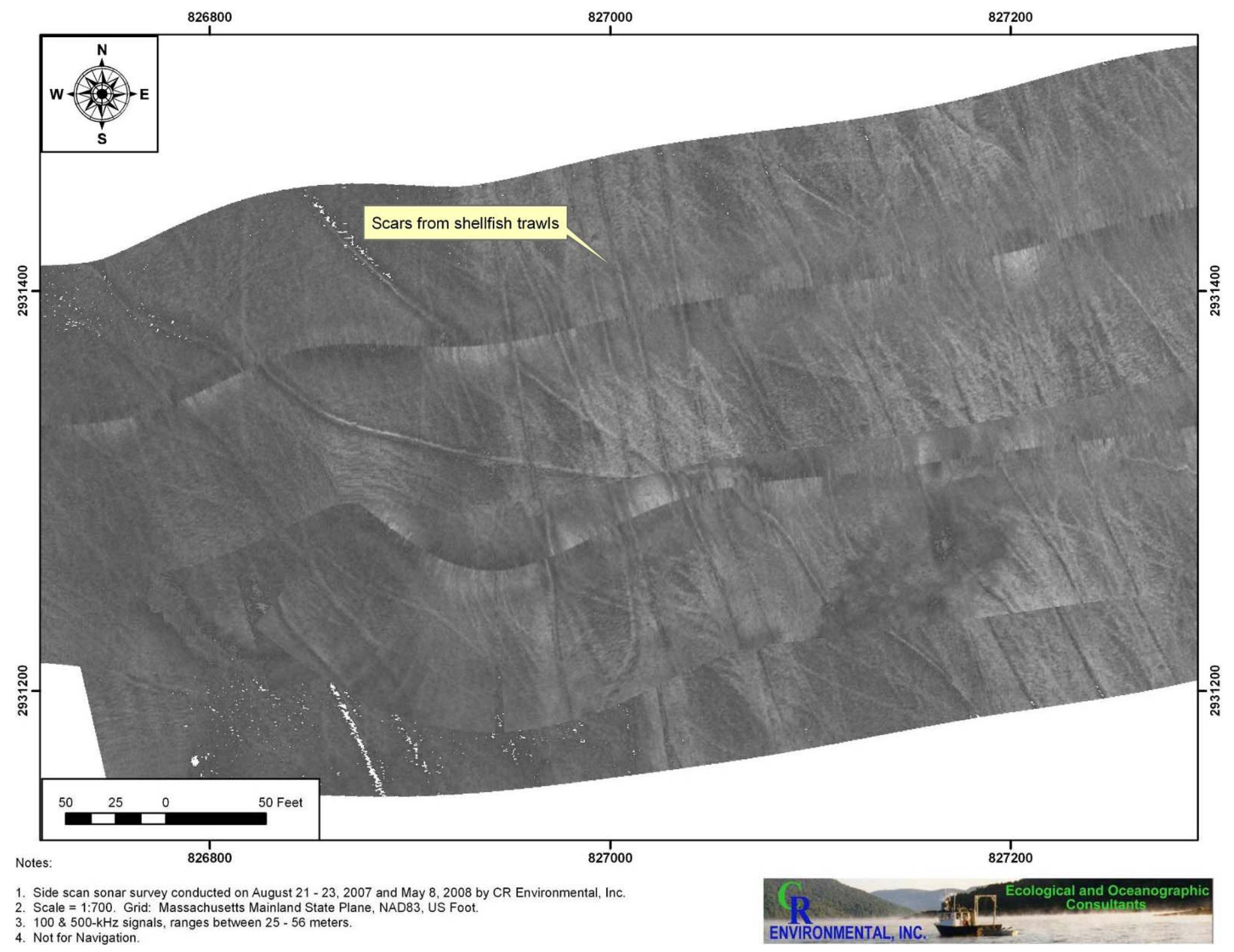


FIGURE 18

ISOPACH MAP DEPICTING THICKNESS OF SURFICIAL REFLECTOR FROM “SHALLOW" SUB-BOTTOM SONAR DATA

1.0 Foot Contour Interval

HULL OFFSHORE WIND PROJECT

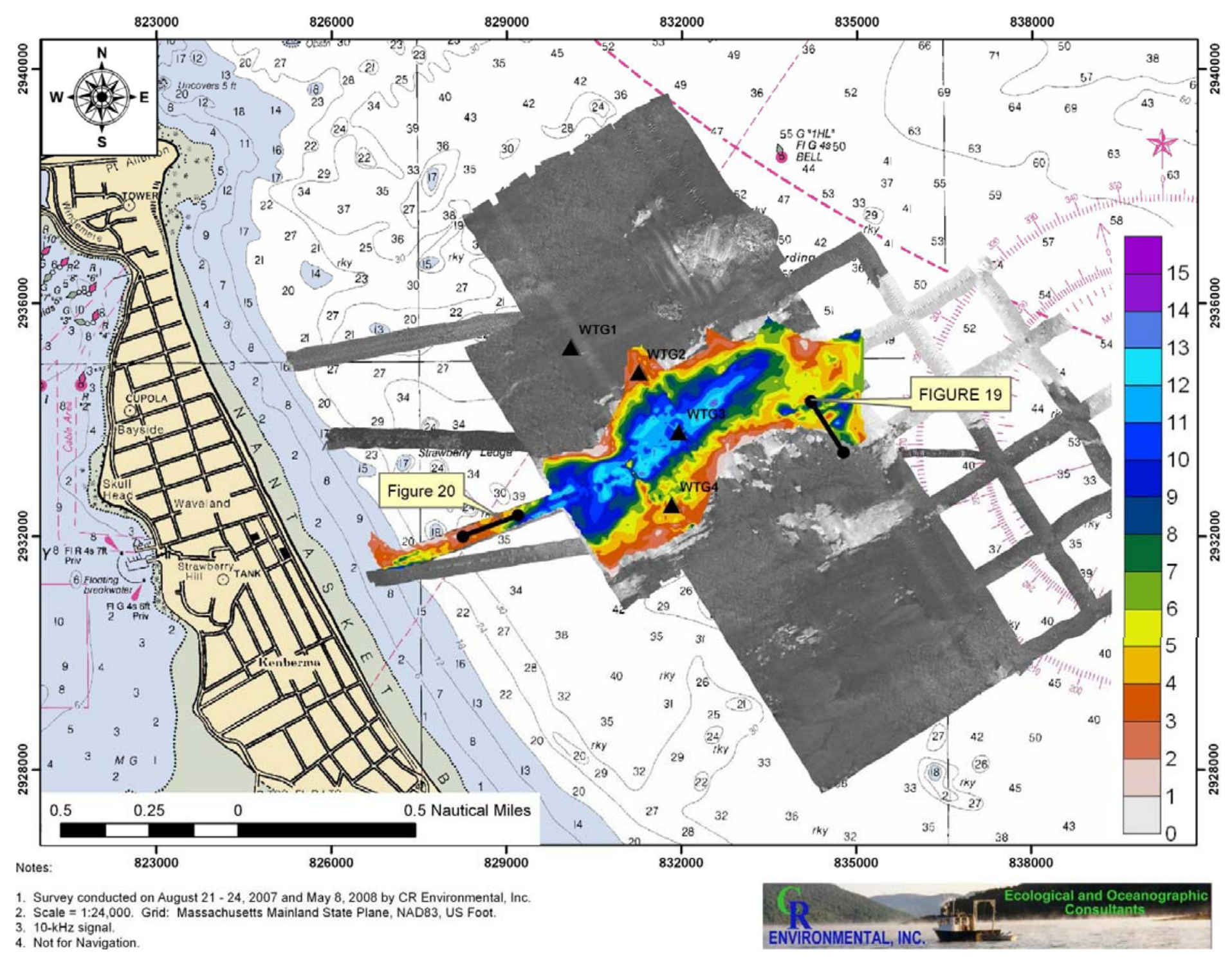


FIGURE 19

ANNOTATED 10-KHZ SUB-BOTTOM SONAR PROFILE

File 20070821162014.odc

(Depths in Feet)

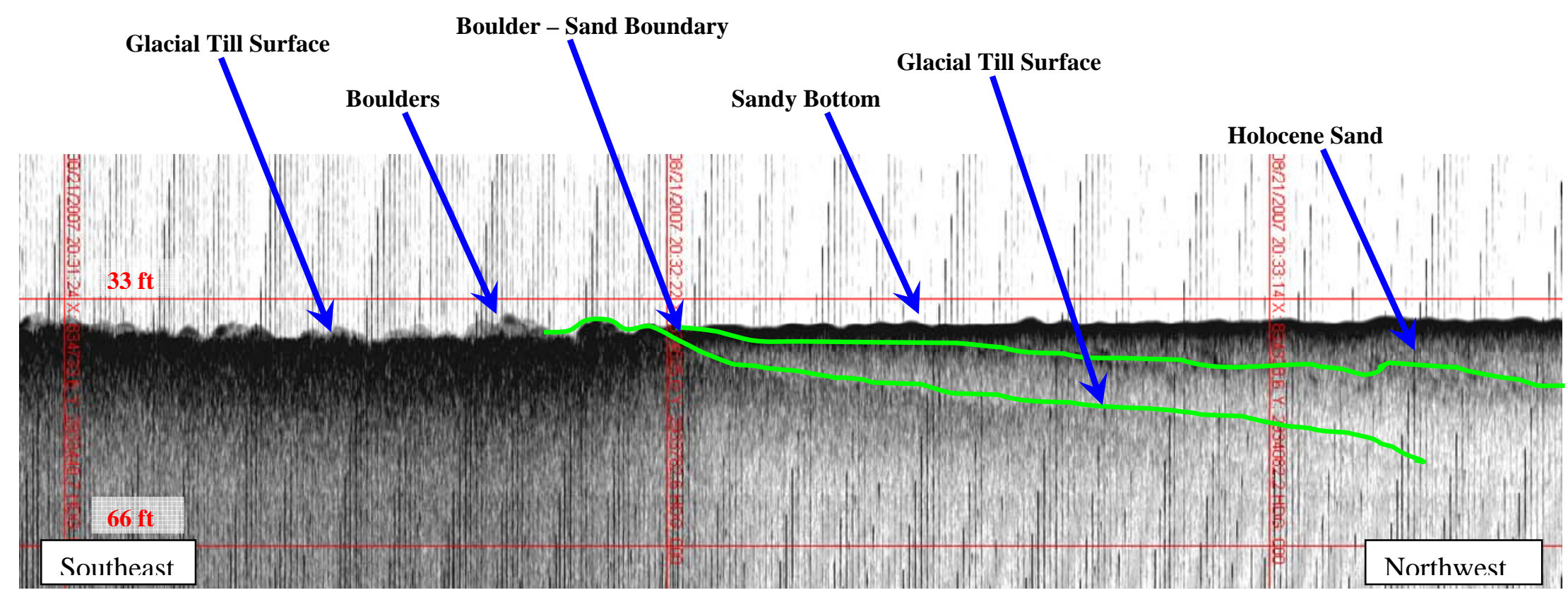


FIGURE 20

\section{ANNOTATED 10-KHZ SUB-BOTTOM SONAR PROFILE} File 20070824090740.odc

(Depths in Feet)

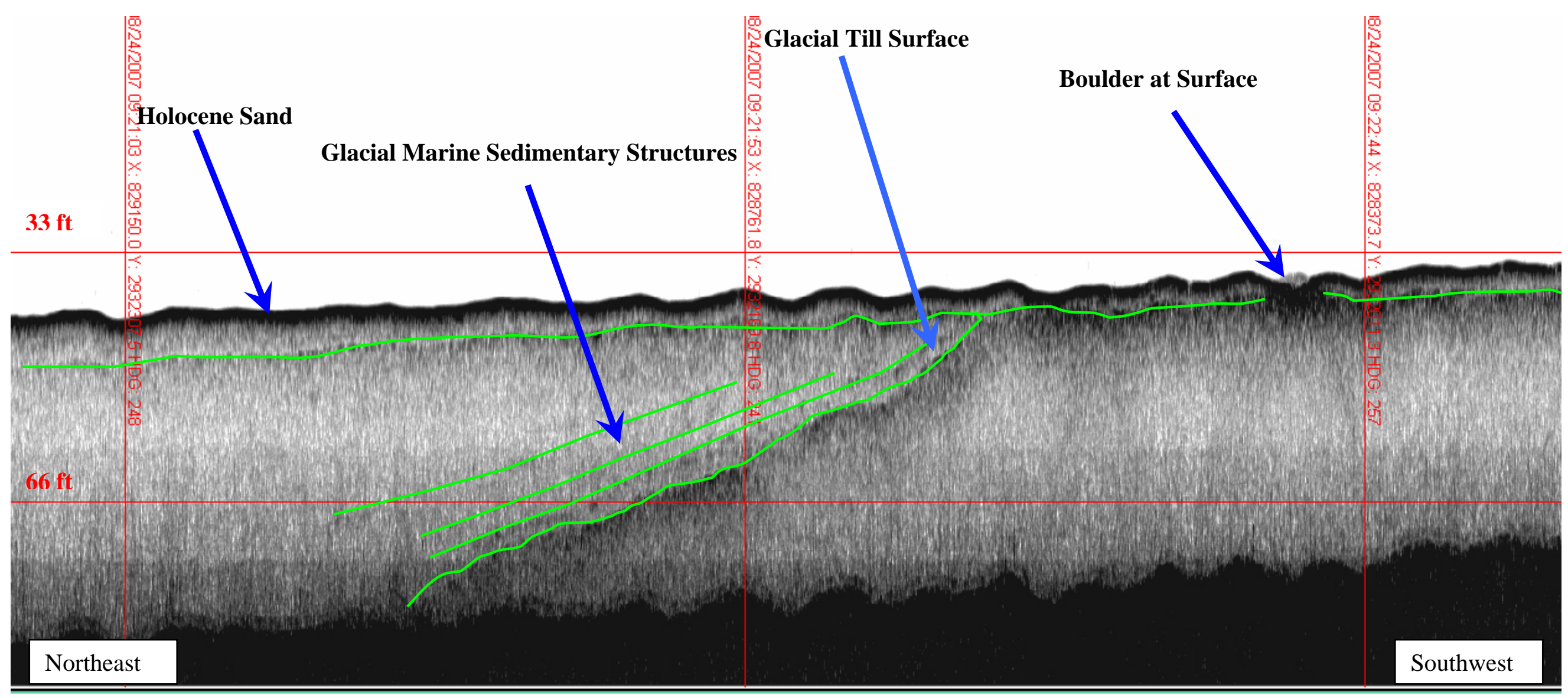


FIGURE 21

ISOPACH MAP DEPICTING THE ESTIMATED MINIMUM DEPTH TO ACOUSTIC BASEMENT 5 Foot Contour Interval

HULL OFFSHORE WIND PROJECT

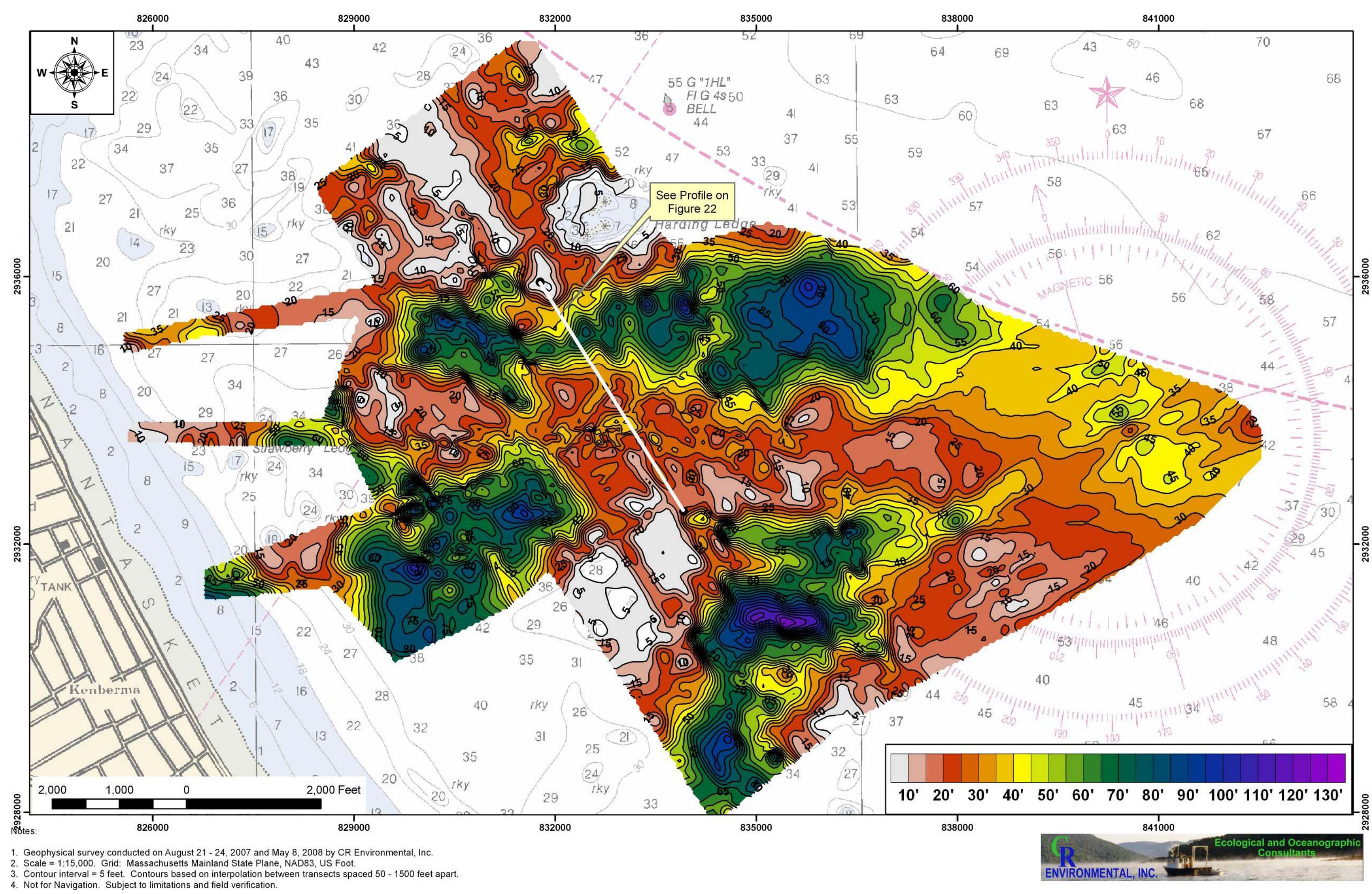


FIGURE 22

SAMPLE 0.5 - $2.0 \mathrm{kHz}$ BOOMER PROFILE

HULL OFFSHORE WIND PROJECT

(Reference Figure 21 for Profile Location)

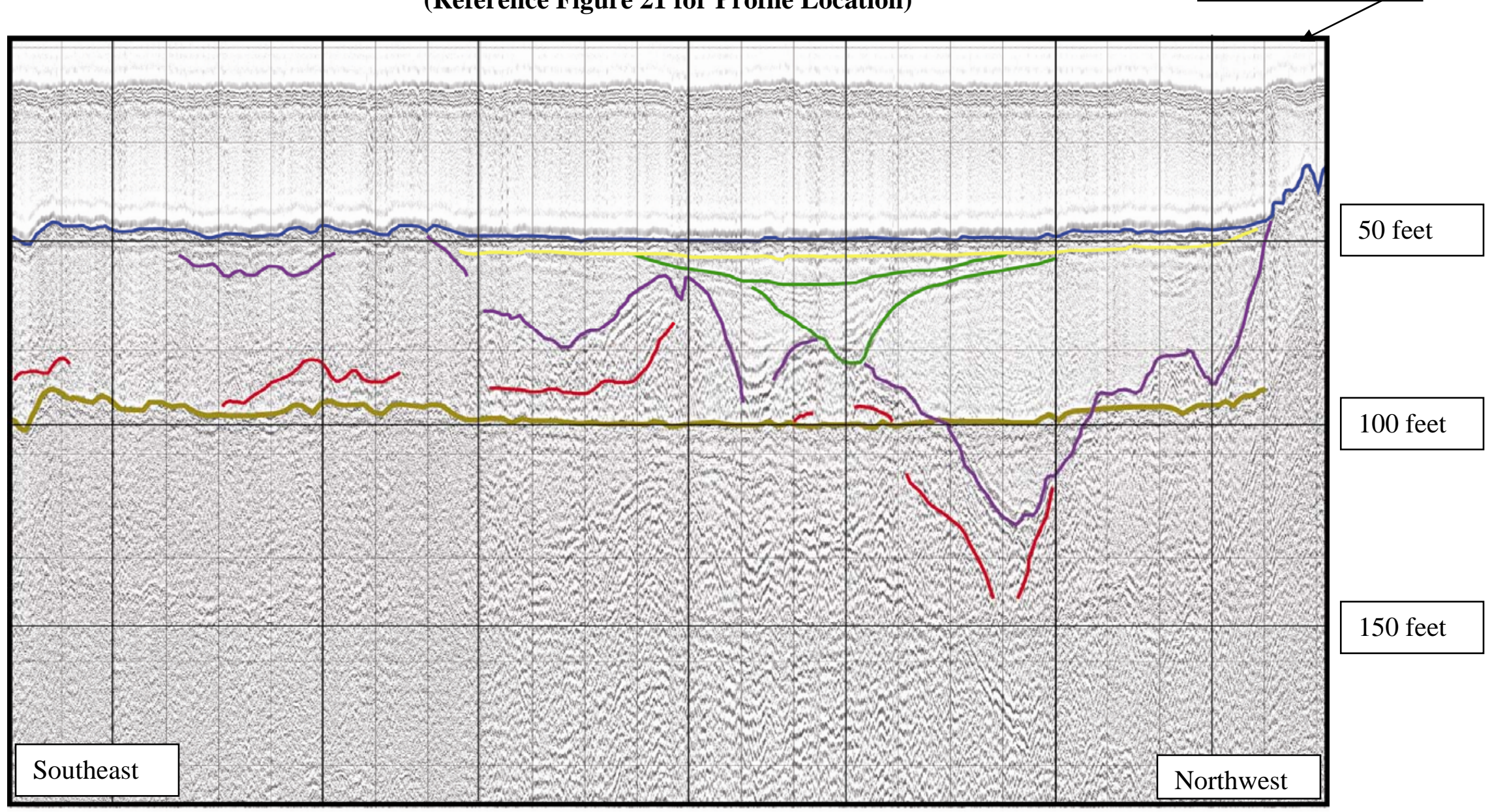

Key Relfectors:

SEAFLOOR

HWF_A_Line_11.seg

1st MULTIPLE

Central portion

All other reflectors (yellow, green, purple) interpreted as the upper bounding surface of a coherent geophysical stratigraphic unit. Confidence in identification of the deepest "red" reflector is lowest.

Vertical lines are spaced 50m apart. Horizontal lines are spaced 20 milliseconds (approximately 50 feet) apart. 
FIGURE 23

MAGNETIC CONTOUR MAP - TOTAL FIELD

1.0 Gamma Contour Interval

HULL OFFSHORE WIND PROJECT

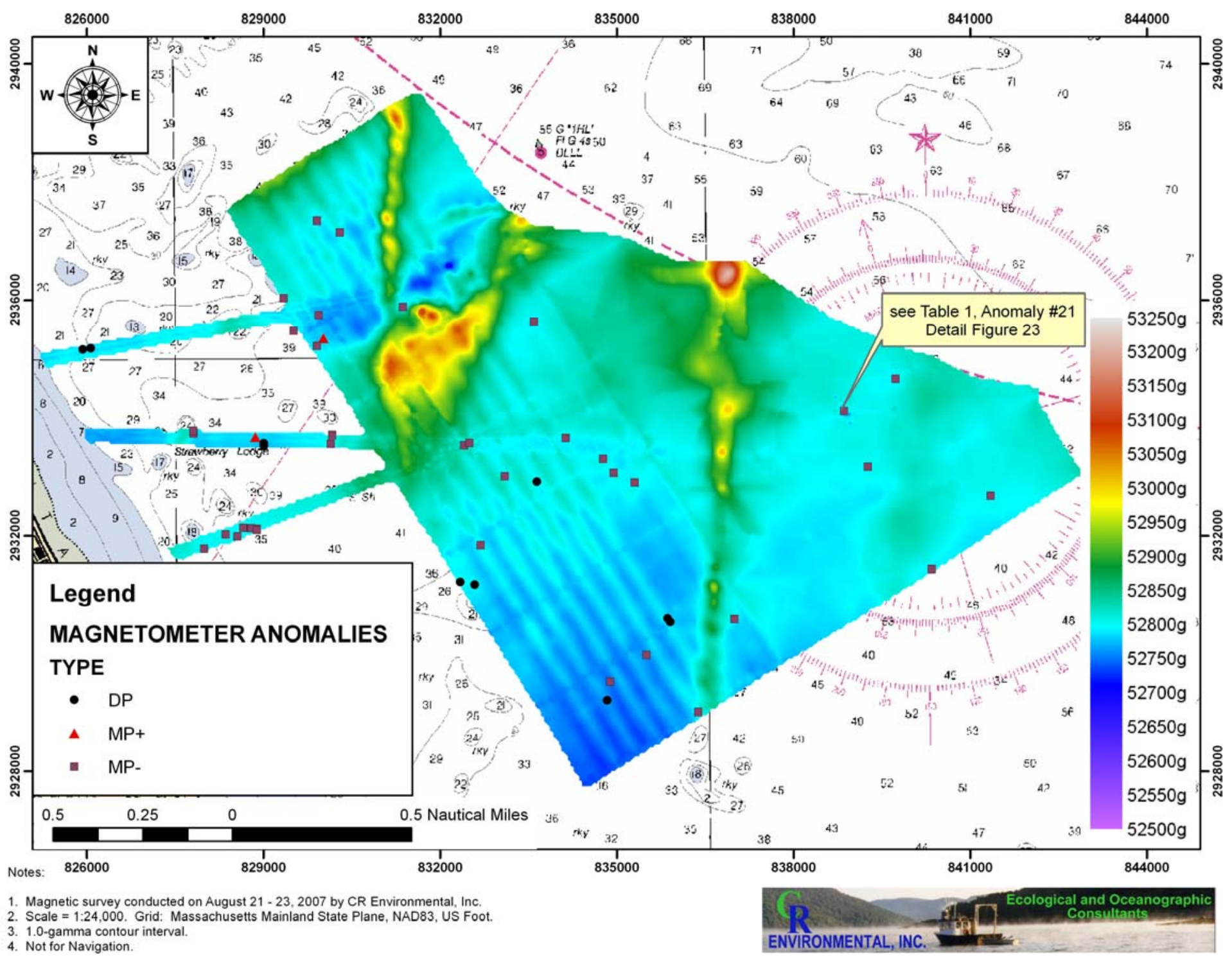


FIGURE 23A

MAGNETIC CONTOUR MAP - 2008 TOTAL FIELD DATA FOR AREA “C” AND CABLE ROUTE NO. 5

4 Gamma Contour Interval

HULL OFFSHORE WIND PROJECT

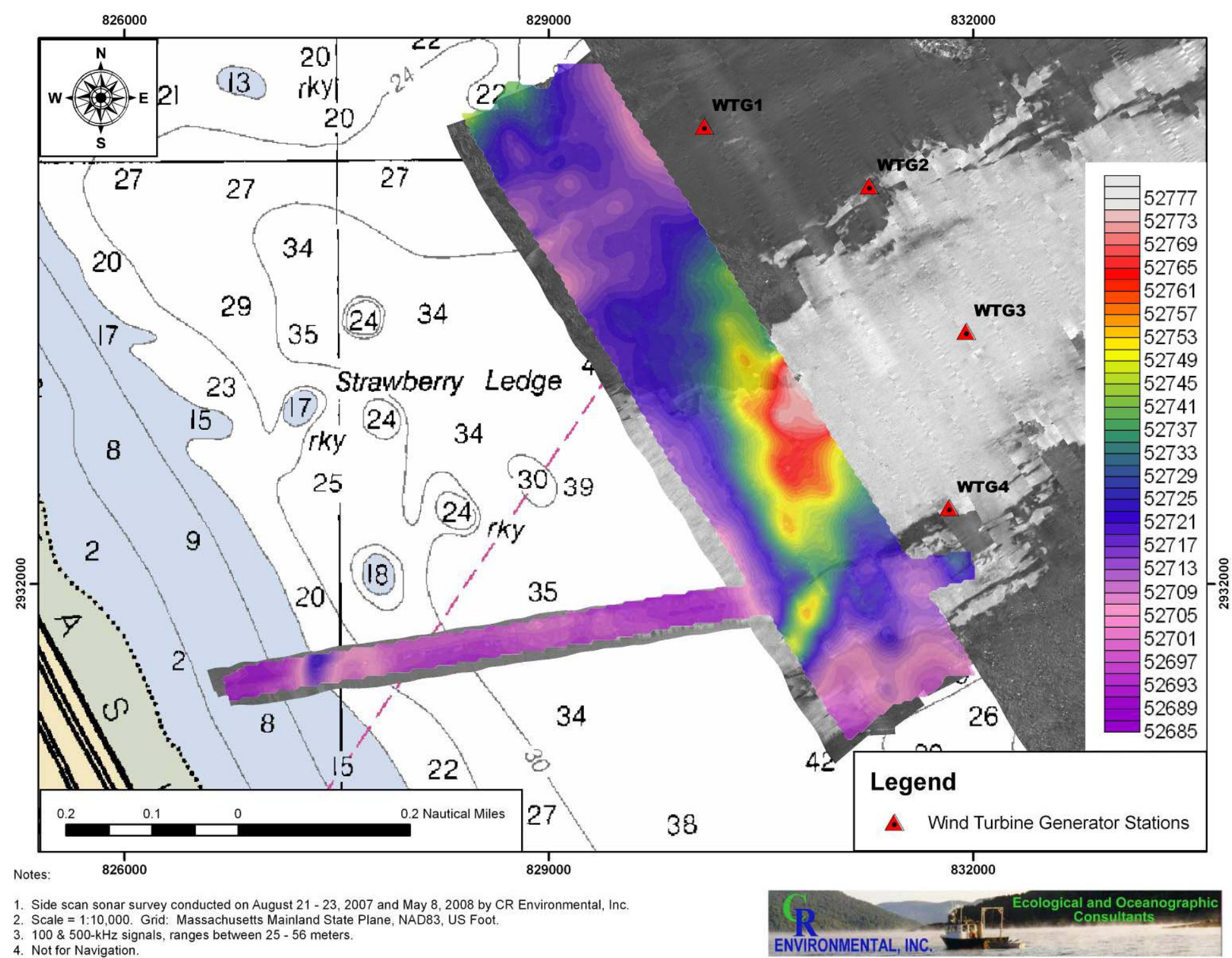




\section{FIGURE 24}

\section{MAGNETIC CONTOUR MAP - POLE REDUCED}

1.0 Gamma Contour Interval

HULL OFFSHORE WIND PROJECT

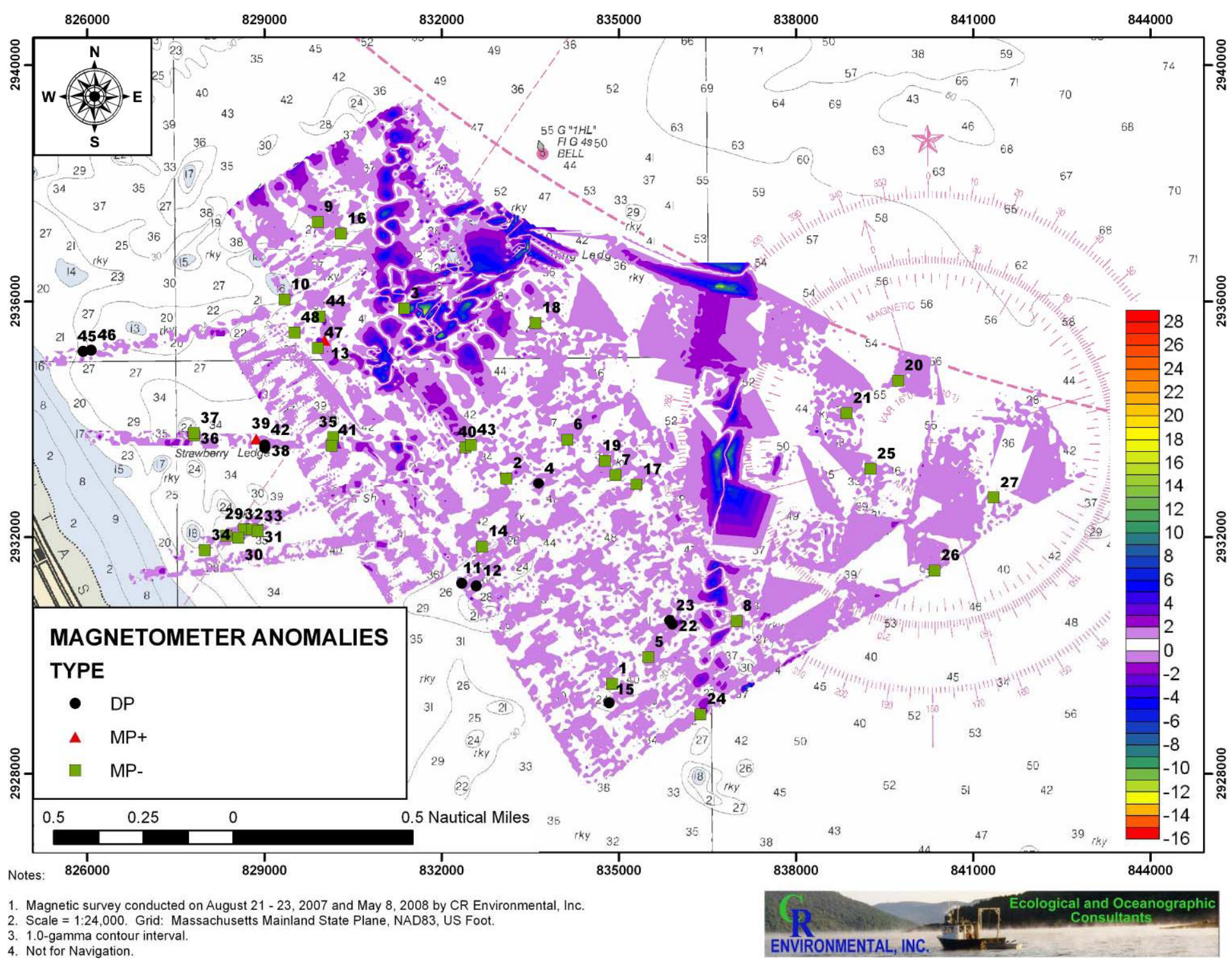

